\title{
Dissecting the Role of GABA Neurons in the VTA versus $\mathrm{SNr}$ in Opioid Reward
}

\author{
${ }^{\circledR}$ Ewa Galaj, ${ }^{1}$ Xiao Han, ${ }^{1}$ Hui Shen, ${ }^{2}$ Chloe J. Jordan, ${ }^{1}$ Yi He, ${ }^{1}$ Bree Humburg, ${ }^{1}$ Guo-Hua Bi, ${ }^{1}$ and \\ Clang-Xiong Xi ${ }^{1}$ \\ ${ }^{1}$ Addiction Biology Unit, Molecular Targets and Medications Discovery Branch, National Institute on Drug Abuse, Intramural Research Program, \\ Baltimore, Maryland 21224, and ${ }^{2}$ Synaptic Plasticity Section, National Institute on Drug Abuse, Intramural Research Program, Baltimore, Maryland \\ 21224
}

Opioid reward has traditionally been thought to be mediated by GABA-induced disinhibition of dopamine (DA) neurons in the VTA. However, direct behavioral evidence supporting this hypothesis is still lacking. In this study, we found that the $\mu$ opioid receptor (MOR) gene, Oprm1, is highly expressed in GABA neurons, with $\sim 50 \%$ of GABA neurons in the substantia nigra pars reticulata $(\mathrm{SNr}), \sim 30 \%$ in the VTA, and $\sim 70 \%$ in the tail of the VTA (also called the rostromedial tegmental nucleus) in male rats. No Oprm1 mRNA was detected in midbrain DA neurons. We then found that optogenetic inhibition of VTA DA neurons reduced intravenous heroin self-administration, whereas activation of these neurons produced robust optical intracranial self-stimulation in DAT-Cre mice, supporting an important role of DA neurons in opioid reward. Unexpectedly, pharmacological blockade of MORs in the SNr was more effective than in the VTA in reducing heroin reward. Optogenetic activation of VTA GABA neurons caused place aversion and inhibited cocaine, but not heroin, self-administration, whereas optogenetic activation of $\mathrm{SNr}$ GABA neurons caused a robust increase in heroin self-administration with an extinction pattern, suggesting a compensatory response in drug intake due to reduced heroin reward. In addition, activation of SNr GABA neurons attenuated heroin-primed, but not cue-induced, reinstatement of drug-seeking behavior, whereas inhibition of SNr GABA neurons produced optical intracranial self-stimulation and place preference. Together, these findings suggest that MORs on GABA neurons in the SNr play more important roles in opioid reward and relapse than MORs on VTA GABA neurons.

Key words: GABA; heroin; $\mu$ opioid receptor; reward; substantia nigra pars reticulata; VTA

Significance Statement

Opioid reward has long been believed to be mediated by inhibition of GABA interneurons in the VTA that subsequently leads to disinhibition of DA neurons. In this study, we found that more $\mu$ opioid receptors (MORs) are expressed in GABA neurons in the neighboring SNr than in the VTA, and that pharmacological blockade of MORs in the SNr is more effective in reducing heroin reward than blockade of MORs in the VTA. Furthermore, optogenetic activation of VTA GABA neurons inhibited cocaine, but not heroin, self-administration, whereas activation of SNr GABA neurons inhibited heroin reward and relapse. These findings suggest that opioid reward is more likely mediated by stimulation of MORs in GABA afferents from other brain regions than in VTA GABA neurons.

Received Apr. 26, 2020; revised Aug. 22, 2020; accepted Sep. 21, 2020.

Author contributions: E.G. and Z.-X.X. designed research; E.G., X.H., H.S., C.J.J., Y.H., B.H., G.H.B., and Z.-X.X. performed research; E.G., X.H., H.S., Y.H., G.H.B., and Z.-X.X. analyzed data; E.G. and Z.-X.X. wrote the paper.

This work was supported by National Institute on Drug Abuse Intramural Research Program Z1A DA000633-01. We thank Dr. Yavin Shaham (National Institute on Drug Abuse Intramural Research Program) for constructive comments and suggestions during the experiments, and critical reading and modifications during the manuscript preparations.

X. Han's present address: Beijing Institute of Pharmacology and Toxicology, Beijing, 100850, China.

Y. He's present address: Department of Neuroscience, University of Pittsburgh, Pittsburgh, Pennsylvania 15260.

The authors declare no competing financial interests.

Correspondence should be addressed to Zheng-Xiong Xi at zxi@mail.nih.gov.

https://doi.org/10.1523/JNEUROSCI.0988-20.2020

Copyright $\odot 2020$ the authors

\section{Introduction}

The neural mechanisms underlying opioid reward and relapse are still not fully understood. Opioid reward has traditionally been thought to be mediated by activation of $\mu$ opioid receptors (MORs) located on GABA neurons within the VTA and opioidinduced disinhibition of adjacent dopamine (DA) neurons (Gysling and Wang, 1983; Johnson and North, 1992; Margolis et al., 2014). This hypothesis was supported by a series of behavioral studies demonstrating that morphine or DAMGO is selfadministered directly into the VTA (Bozarth and Wise, 1981; Welzl et al., 1989; David and Cazala, 1994; Devine and Wise, 1994) and intra-VTA infusions of opioids produce conditioned 
place preference (Phillips and LePiane, 1980; Bals-Kubik et al., 1993) or support self-administration (Zangen et al., 2002). In contrast, MOR antagonists, when infused into the VTA, block morphine-induced conditioned place preference (Wise, 1989; Olmstead and Franklin, 1997). Chemogenetic inhibition of VTA DA neurons inhibits intravenous heroin self-administration in mice (Corre et al., 2018), supporting an important role of DA in opioid reward. In contrast, some studies do not support this dogma: DA receptor antagonists or 6-OHDA lesions of DA terminals in the NAc decrease cocaine but not heroin self-administration (Ettenberg et al., 1982; Pettit et al., 1984; Dworkin et al., 1988; Gerrits et al., 1994; Badiani et al., 2011).

At present, it is unknown whether disinhibition of DA neurons is mediated primarily by opioid-induced inhibition of local GABA neurons within the VTA or of GABAergic afferents from other brain regions (Galaj et al., 2020b). Early receptor binding assays indicate that the MOR expression level in the VTA is very low as compared to other brain regions (Tempel and Zukin, 1987; Méndez et al., 2003), suggesting that the VTA may not be a primary site of opioid action. This is further supported by the findings that VTA DA neurons receive GABA inputs mainly from other brain regions, including the NAc, ventral pallidum, and rostromedial tegmental nucleus (RMTg) (Bolam and Smith, 1990; Kalivas, 1993; Tepper and Lee, 2007; Watabe-Uchida et al., 2012; Hjelmstad et al., 2013). Electrophysiological studies measuring GABA-mediated inhibitory postsynaptic currents (IPSCs) on VTA DA neurons indicate that opioids can induce $~ 50 \%$ inhibition of IPSCs evoked from the RMTg, $\sim 30 \%$ from the ventral pallidum, $\sim 20 \%$ from the NAc, and $\sim 10 \%$ from VTA interneurons (Matsui and Williams, 2011; Jhou et al., 2012; Hjelmstad et al., 2013; Matsui et al., 2014), suggesting that the RMTg might be one of the major brain regions sending opioidsensitive GABAergic inputs to VTA DA neurons.

The SNr is another region adjacent to the VTA and the substantia nigra pars compacta (SNc), and displays high MOR binding in autoradiography assays (Tempel and Zukin, 1987; Méndez et al., 2003) and high densities of GABA neurons (Tepper and Lee, 2007). However, the role of the $\mathrm{SNr}$ in opioid action is largely unknown. In this study, we studied the role of MORs on GABAergic neurons in the VTA and SNr in opioid reward and relapse. We first examined GABA neuron distributions in the midbrain and MOR distributions in different phenotypes of neurons in the VTA, SNc, SNr, and RMTg using immunocytochemistry and RNAscope ISH techniques. We then used pharmacological approaches to block MORs in the VTA versus SNr to compare the changes in heroin self-administration and reinstatement. Last, we used optogenetic approaches to study the role of $\mathrm{DA}$ versus $\mathrm{GABA}$ neurons in the VTA, $\mathrm{SNc}$, and $\mathrm{SNr}$ in brain reward function and in heroin self-administration and reinstatement (relapse) in transgenic mice. We found that more MORs are expressed in GABA neurons of the SNr than of the VTA, and that optogenetic activation of GABA neurons in the $\mathrm{SNr}$, but not VTA, reduced opioid reward and relapse.

\section{Materials and Methods}

Subjects

Male Long-Evans rats (Charles River Laboratories, initially weighing 250-300 g), male and female DAT-ires-cre knock-in (DAT-cre, stock \#020080) and vGAT-ires-cre knock-in (vGAT-cre, stock \#028862) mice with a C57BL/6J genetic background (weighing 30-40 g, The Jackson Laboratory), were used in the present experiments. During experimentation, animals were housed individually in climate-controlled animal colony rooms on a reversed $12 \mathrm{~h}$ light-dark cycle (lights off at 7:00 A.M. and on at 7:00 P.M.) with free access to food and water. All experiments were conducted during the animals' active period (dark cycle). The housing conditions and care of the animals were consistent with the National Institutes of Health's Guide for the care and use of laboratory animals. The protocols used in the present experiments were approved by the National Institute on Drug Abuse Animal Care and Use Committee.

\section{Surgery}

The intravenous surgery procedure for heroin self-administration in rats or mice was the same as we reported previously (Xi et al., 2011; Galaj et al., 2020a). Briefly, a Microrenathane catheter was implanted in the right jugular vein, and its free end fed subcutaneously along the scapula was connected to a 22 gauge stainless connector that was mounted to the skull using stainless-steel screws and dental acrylic. To ensure its patency, the catheter was flushed daily with gentamicin and heparin after surgery.

For the intracranial microinjections in rats, two stainless-steel cannulae were implanted under deep anesthesia into the VTA (AP - 5.6, ML \pm 2.0 , and DV -7.4 ; at $10^{\circ}$ angle away from the midline) or SNr (AP $-5.52, \mathrm{ML} \pm 3.06$, and DV -8.15). Obturators, extending $1 \mathrm{~mm}$ beyond the cannulae, were inserted into the cannulae to prevent blockage and remained there at all times, except during microinjections.

For the optogenetic experiments, DAT-cre or vGAT-cre mice were anesthetized with ketamine/xylazine (100 and $10 \mathrm{mg} / \mathrm{kg}$, respectively). For intra-VTA, intra-SNc, or intra-SNr microinjections of virus, a custom-made 30 gauge stainless injector was used to infuse inhibitory halorhodopsin (AAV5-EF1 $\alpha$-DIO-NpHR-EYFP), excitatory channelrhodopsin (AAV5-EF1 $\alpha$-DIO-ChR2-EYFP), or the control virus (AAV5EF1 $\alpha$-DIO-EYFP, e.g., AAV-EYFP). Individual adeno-associated viruses (AAVs, UNC Vector Core) were delivered bilaterally to the VTA (AP - 3.1, ML $\pm 0.8, \mathrm{DV}-4.25$ ), SNc (AP 3.1, ML 1.6, DV 4.0 for the $\mathrm{SNc})$, or $\mathrm{SNr}\left(\mathrm{AP}-3.2, \mathrm{ML} \pm 2.19, \mathrm{DV}-4.57\right.$; at $10^{\circ}$ angle away from the midline) using a $10 \mu \mathrm{l}$ Nanofil syringe and Micro 4 Pump (World Precision Instruments) at a rate of $50 \mathrm{nl} / \mathrm{min}$ for a total volume of $250 \mathrm{nl}$ per side in the SNr and $150 \mathrm{nl}$ per side in the VTA. Bilateral custommade ferrule fibers were implanted $(200 \mu \mathrm{m}$ inner diameter, Doric Lenses) $0.5 \mathrm{~mm}$ above the injection site. For a mouse heroin self-administration experiment, in addition to the intra-VTA or intra-SNr injections of AVV-ChR2 virus, DAT-cre or vGAT-cre mice were catheterized in the right jugular vein, as described previously (Xi et al., 2011).

\section{Drugs}

Heroin-hydrochloride (provided by National Institute on Drug Abuse pharmacy) was dissolved in $0.9 \%$ saline to achieve final doses of 0.05 , 0.025 , or $0.0125 \mathrm{mg} / \mathrm{kg} /$ infusion (for self-administration experiments). Naloxonazine and naloxone (purchased from Tocris Bioscience) were dissolved in $0.9 \%$ saline to achieve final doses of 2 and $4 \mu \mathrm{g}$ or doses of 3 and $10 \mu \mathrm{g} / 0.5 \mu \mathrm{l} /$ side, respectively.

\section{Apparatus}

Rat or mouse self-administration was conducted in standard operant chambers (Med-Associates), each housed in a sound-attenuating box and equipped with two retractable levers, a white light/tone above the active lever, and a drug line connected to a syringe pump. In optical intracranial self-stimulation (oICSS) and real-time place preference (RTPP) experiments, conducted in standard conditioning chambers (Med Associates; Any-Maze), mice were gently connected to a cable attached to an optical swivel, which was in turn connected to a $473 \mathrm{~nm}$ laser or $532 \mathrm{~nm}$ laser tuned for ChR2 or NpHR stimulation, respectively. Computer software controlled a pulse generator that controlled the laser.

\section{Procedures}

Experiment 1: GAD67 immunostaining. To determine the distributions of GABAergic neurons in the VTA, SNc, and SNr, rats were anesthetized with sodium pentobarbital $(100 \mathrm{mg} / \mathrm{kg}$, i.p.) and intracardially perfused with ice-cold $0.9 \%$ saline followed by $4 \%$ PFA. Brains were coronally sectioned at $30 \mu \mathrm{m}$. The brain sections were processed for immunohistochemistry assays to observe glutamic acid decarboxylase 67 
GAD67, an enzyme that converts glutamate to GABA). Briefly, freefloating coronal sections $(n=2)$ were incubated for $1 \mathrm{~h}$ in PB supplemented with $4 \%$ BSA and $0.3 \%$ Triton X-100. Sections were then incubated with cocktails of primary antibodies (mouse monoclonal antiGAD67 antibody, Millipore, MAB5406; 1:500) overnight at $4^{\circ} \mathrm{C}$. After three rinses (10 min each) in $\mathrm{PB}$, sections were incubated in a fluorescently labeled secondary antibody (AlexaFluor-594 goat anti-mouse, 1:500; Invitrogen) for $1 \mathrm{~h}$ at room temperature. After rinsing, sections were mounted on gelatin-coated slides with $50 \%$ buffered glycerol. Mounted sections were coverslipped with DAPI nuclear counterstain (H-1200, Vector Laboratories). Fluorescent images were collected with an FV1000 Confocal System (Olympus) using manufacturer-provided software.

Experiment 2: RNAscope ISH for Oprm1, DAT, and GAD1. To determine the cellular distributions of MOR mRNA in the midbrain, we used RNAscope ISH to image Oprm1, DAT, and GAD1 mRNAs in the VTA, $\mathrm{SNc}$, SNr, and RMTg. Rat brains were extracted by rapid decapitation and immediately submerged in 2-methyl-butane to be then stored in $-80^{\circ} \mathrm{C}$ until ready for use. Coronal sections of rat midbrain were collected at $16 \mu \mathrm{m}$ thickness on the Superfrost Plus slides to be then dehydrated in graduated ethanol (PBS, 50\%, 70\%, and 100\% ethanol). Using RNAscope Reagent Kit (Advanced Cell Diagnostics), the midbrain sections were incubated first in Protease-Pretreat 4 solution (room temperature, $20 \mathrm{~min}$ ), rinsed twice in $\mathrm{dH}_{2} \mathrm{O}$, and then treated with Oprm1, DAT, and $G A D 1$ probes for $2 \mathrm{~h}$ at $40^{\circ} \mathrm{C}$. To determine Oprm 1 mRNA expression in midbrain GABA and DA neurons in rats, we used Rn-MOR-2 and Rn-GAD1-3, and Rn-Slc6a3-C3 probes (Advanced Cell Diagnostics). After double rinse in wash buffer (Advanced cell Diagnostics), the sections were treated with AMP $1\left(30 \mathrm{~min}, 40^{\circ} \mathrm{C}\right)$, AMP $2\left(15 \mathrm{~min}, 40^{\circ} \mathrm{C}\right)$, AMP 3 $\left(30 \mathrm{~min}, 40^{\circ} \mathrm{C}\right)$, and AMP 4 Alt $\mathrm{A}\left(15 \mathrm{~min}, 40^{\circ} \mathrm{C}\right)$ with double rinse in $\mathrm{PB}$ between each amplification step. Next, a drop of DAPI was added to each slide, followed by fluorescent mounting medium (Fluoro-Gel; \#17985, Electron Microscopy Science) and coverslip.

Images were taken on KEYENCE BZ-X800 Fluorescence Microscope from three sections obtained from 3 rats at 4,20,40, and $60 \times$ magnification. A number of DAPI-positive cells, expressing GAD1 or Oprm1 + GAD1, were counted at $40 \times$ magnification using Image J software.

Experiment 3: heroin self-administration in rats. To determine the role of MORs in the VTA versus $\mathrm{SNr}$ in heroin self-administration, Long Evans rats were trained to self-administer heroin $(0.05 \mathrm{mg} / \mathrm{kg} / \mathrm{inf})$ under a fixed ratio (FR1) schedule of reinforcement during daily $3 \mathrm{~h}$ sessions. Responding on the active lever resulted in the intravenous delivery of heroin and presentation of the light + tone complex stimulus above the active lever. Responses on the inactive lever were counted but had no consequences. Once animals demonstrated a pattern of stable responding, defined as $<20 \%$ of variability in daily heroin intake across three consecutive sessions, and an active/inactive lever press ratio exceeding $2: 1$, they (24 rats with intra-SNc guide cannula implantations) were divided into three groups; each group $(n=7$ or 8$)$ of rats received one of three doses of naloxonazine $(0,2$, or $4 \mu \mathrm{g} / 0.5 \mu \mathrm{l} /$ side $)$ or naloxone $(0,3$, or $10 \mu \mathrm{g} / 0.5 \mu \mathrm{l} / \mathrm{side})$. Immediately before the test session, obturators were removed and bilateral intra-SNr microinjections of one of three doses were delivered using two $10 \mu \mathrm{l}$ Nanofil syringes placed in a microsyringe pump (BASI). The injections were delivered over $60 \mathrm{~s}$, and the microinjectors were kept in place for an additional $60 \mathrm{~s}$ to allow the drug to diffuse. Next, the obturators were inserted back into the cannulae, and the rats were placed in the operant chamber for a self-administration session. After the drug test on heroin self-administration maintained by $0.05 \mathrm{mg} / \mathrm{kg} /$ infusion of heroin, the animals were trained to self-administer lower doses of heroin $(0.025 \mathrm{mg} / \mathrm{kg} /$ infusion, followed by $0.0125 \mathrm{mg} /$ $\mathrm{kg} /$ infusion). After stable self-administration was achieved, three groups of rats received intra-SNr microinjections of naloxonazine again. Each animal was tested with one dose of naloxonazine at three different doses of heroin.

To determine whether intra-VTA microinjections of naloxonazine produce similar effects on heroin self-administration, additional groups of rats were surgically prepared for intravenous heroin self-administration and intra-VTA microinjections. Rats underwent the same procedure as described above where they self-administered heroin from
$0.05 \mathrm{mg} / \mathrm{kg} /$ infusion to $0.025 \mathrm{mg} / \mathrm{kg} / \mathrm{kg}$ and then to $0.0125 \mathrm{mg} / \mathrm{kg} / \mathrm{infu}-$ sion. After the stable self-administration was achieved, the effects of intra-VTA naloxonazine $(0,2$, or $4 \mu \mathrm{g} / 0.5 \mu \mathrm{l} /$ side $)$ on heroin self-administration maintained by different doses of heroin were evaluated.

Experiment 4: heroin- or cue-induced reinstatement of drug-seeking in rats. In this experiment, we wanted to determine whether MORs in the SNr play a role in reinstatement of drug-seeking. Rats with a history of heroin self-administration underwent extinction training for 3 weeks. Each extinction session was $3 \mathrm{~h}$ long, and responding on either lever produced no consequences (i.e., no heroin infusion, no heroin-associated cue lights and tones). This phase continued until the extinction criteria were met $(<20$ lever presses for three consecutive sessions). Then, the animals $(n=24)$ were divided into three groups, and each group of rats received one of three naloxonazine doses $(0,2$, or $4 \mu \mathrm{g} / 0.5 \mu \mathrm{l} / \mathrm{side})$, before the cue-induced reinstatement test. Two presentations of the drug cues (light/tone/pump) were made 2 min apart at the beginning of the session. Each response on the active lever was reinforced with the drug cues (but no heroin). Responding on the inactive lever produced no consequences.

The animals then underwent the second phase of heroin self-administration $(0.0125 \mathrm{mg} / \mathrm{kg} / \mathrm{inf})$ followed by extinction to be then tested for heroin-primed reinstatement of drug-seeking. Before the reinstatement session, rats were pretreated with intra-SNr naloxonazine at doses of $(0$, 2 , or $4 \mu \mathrm{g} / 0.5 \mu \mathrm{l} / \mathrm{side})$ and then injected with heroin $(1 \mathrm{mg} / \mathrm{kg}$, i.p.) to induce reinstatement of drug-seeking. Each response on the active lever was reinforced with the drug cues (but with no heroin). Responding on the inactive lever produced no consequences.

Experiment 5: optical RTPP in mice. Here we used DAT-cre or vGAT-cre mice expressing intra-SNr excitatory ChR2, inhibitory NpHR, or control virus, in a real-time place preference paradigm to determine whether optical manipulation of VTA DA neurons, VTA GABA neurons, or SNr GABA neurons is rewarding or aversive. Briefly, vGAT-cre mice were connected to a laser system (OEM Laser Systems) by two sheathed optic fibers (200 $\mu \mathrm{m}$ core diameter, Precision Fiber Products) and FC/FC fiber rotary joint (Doric). Mice were first pre-exposed to the RTPP apparatus for $15 \mathrm{~min}$ on 2 consecutive days. Over the next 5 sessions, either blue light $(473 \mathrm{~nm}, 10 \mathrm{~mW} /$ side, $50 \mathrm{~Hz}, 5 \mathrm{~ms}$ pulse duration, for ChR2, eYFP groups) or green light $(532 \mathrm{~nm}, 10 \mathrm{~mW} /$ side, constant, for NpHR group) was delivered via computer-controlled lasers (OEM Laser Systems) that were programmed to turn on when the mouse fully entered the light-paired chamber (Any-Maze). The duration of the stimulation was contingent on the time the animal spent in the laserpaired compartment. For half of the animals, the laser was paired with their initially preferred compartment and for the other half with the least preferred compartment.

Experiment 6: oICSS in mice. To further evaluate whether activation of midbrain DA neurons or inhibition of midbrain GABA neurons is rewarding, we trained DAT-cre or vGAT-cre mice to press a lever for oICSS. DAT-cre or vGAT-cre mice expressing ChR2, NpHR, or eYFP in DA or GABA neurons in the VTA, SNc, or SNr were connected to a 473 or $532 \mathrm{nM}$ wavelength laser (OEM Laser Systems) emitting blue or green light contingent on lever responding. During each $2 \mathrm{~h}$ session, each press on the active lever activated the light stimulus above the lever and delivered of a $1 \mathrm{~s}$ pulse train of blue light stimulation $(473 \mathrm{~nm}, 10 \mathrm{~mW}, 5 \mathrm{~ms}$ duration, $25 \mathrm{~Hz}$ ) causing $\mathrm{DA}$ neuron depolarization or continuous $532 \mathrm{~nm}$ green light stimulation ( $10 \mathrm{~mW}$, for $20 \mathrm{~s}$ ) causing hyperpolarization of GABA neurons. Pressing the inactive lever yielded no stimulation. Following establishment of lever-pressing for oICSS, animals were presented with a series of six different stimulation frequencies $(100,50$, $25,10,5$, and $1 \mathrm{~Hz}$ ) in descending order to obtain rate-frequency response curves. Animals were allowed to respond for $10 \mathrm{~min}$ per stimulation frequency.

Experiment 7: mouse heroin self-administration combined with optical stimulation. To determine the role of DA or GABA neurons in the VTA or SNr in heroin self-administration, DAT-cre mice with NpHR expression in VTA DA neurons or vGAT-cre mice with ChR2 expression in GABA neurons in the VTA or SNr were trained to self-administer heroin $(0.05 \mathrm{mg} / \mathrm{kg} /$ infusion$)$, as described above. After showing a pattern of stable responding, mice continued to self-administer heroin 
A
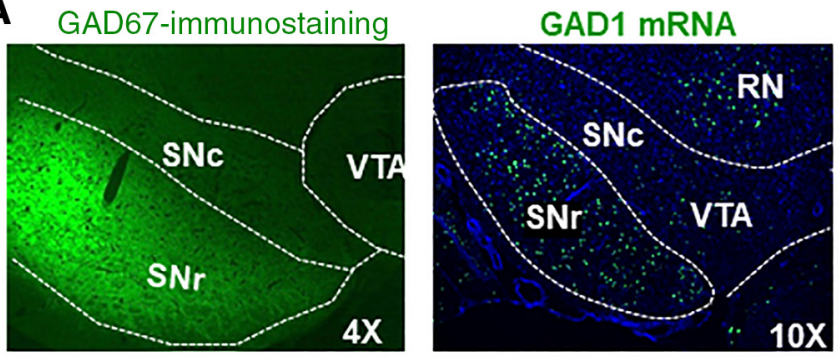

B

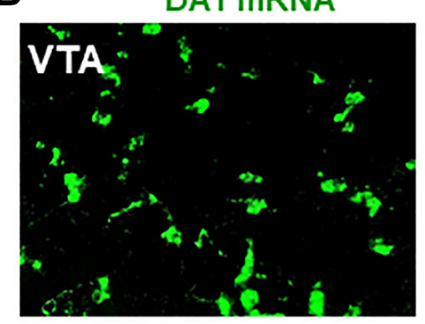

C
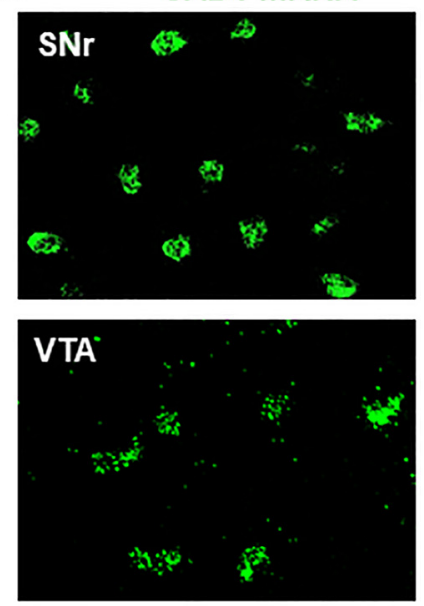
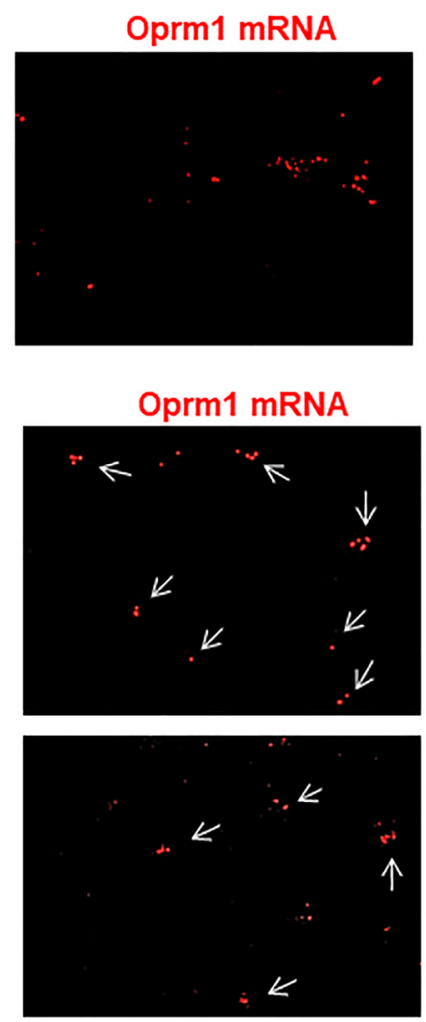

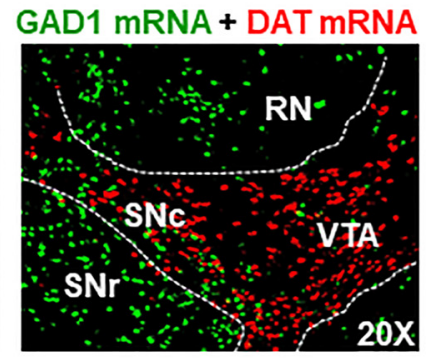

\section{$\mathrm{DAT}+$ Oprm1 + DAPI}

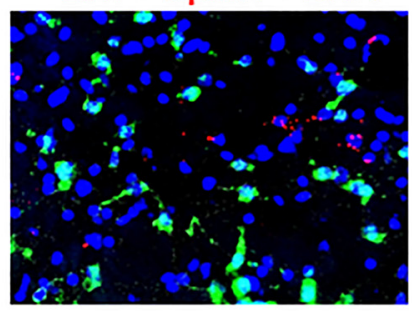

GAD1 + Oprm1 + DAPI
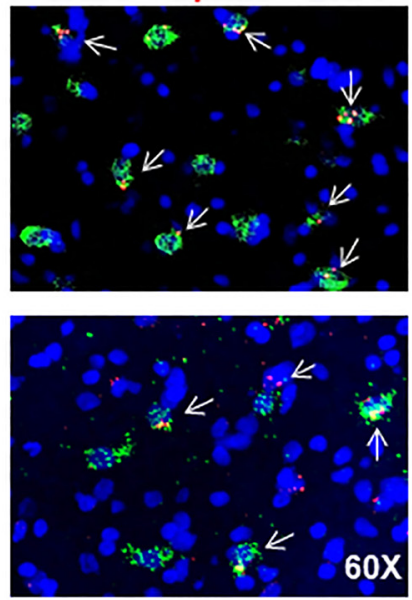

Figure 1. MOR expression in midbrain DA neurons versus GABA neurons in rats. $A$, GAD67 immunostaining and RNAscope ISH results indicating that GAD1-positive GABA neurons are mainly distributed in the SNr and red nucleus (RN), but not in the VTA and SNc where the majority of neurons are TH-positive DA neurons. B, MOR (Oprm1) RNAscope results, indicating that MORs are not expressed in VTA DA neurons. C, MOR (Oprm1) RNAscope results indicate that MORs are expressed in subpopulations of GAD1-positive GABA neurons in both the SNr and VTA. Images were taken under $60 \times$ magnification ( $n=3$ per group).

such that each press on the active lever activated the syringe pump, heroin cues (lights/tones) for $4.5 \mathrm{~s}$ and the green laser $(532 \mathrm{~nm}, 10 \mathrm{~mW} /$ side, constant stimulation for $20 \mathrm{~s}$ for NpHR expression in VTA DA neurons) or blue laser $(473 \mathrm{~nm}, 10 \mathrm{~mW} /$ side, $50 \mathrm{~Hz}, 5 \mathrm{~ms}$ pulse duration, for $1 \mathrm{~s}$ for ChR2 eYFP expression in GABA neurons). Mice were trained to self-administer three doses of heroin according to the sequence of $0.05,0.025$, and $0.0125 \mathrm{mg} / \mathrm{kg} /$ infusion, and tested under the same conditions. An additional group of vGAT-cre mice with ChR2 expression in VTA GABA neurons were initially trained for cocaine $(0.5 \mathrm{mg} / \mathrm{kg} / \mathrm{infu}-$ sion) self-administration. The effects of optical activation of VTA GABA neurons on cocaine self-administration were evaluated.

Experiment 8: reinstatement test combined with optical stimulation in mice. To further examine the role of SNr GABA neurons in opioid action, we used an optogenetic approach to assess the effects of optical activation of SNr GABA neurons on heroin-primed reinstatement of heroin seeking. Here vGAT-cre mice with a history of heroin selfadministration underwent extinction training as described above. After meeting the extinction criteria $(<20$ lever presses in 3 consecutive sessions), mice were injected with heroin ( $1 \mathrm{mg} / \mathrm{kg}$, i.p.) and then tested for drug-primed reinstatement of heroin seeking. Active lever presses turned on the heroin cues (light/tone/pump) and the $473 \mathrm{~nm}$ laser delivering $50 \mathrm{~Hz}$ stimulation $(10 \mathrm{~mW})$ for $20 \mathrm{~s}$. After two additional extinction sessions, drug-primed reinstatement test was repeated without the laser activation where each active lever press activated only heroin cues (pump/light/tone). Presses on the inactive lever had no consequences.

Experiment 9: food self-administration combined with optical stimulation. Here we used an optogenetic approach to determine whether $\mathrm{SNr}$ GABA neurons also play a role in nondrug reward. Briefly, vGAT-cre mice with ChR2 expression in SNr GABA neurons were trained to selfadminister food under a FR1 schedule of reinforcement during daily $30 \mathrm{~min}$ sessions. Presses on the active lever caused a delivery of food pellet and activation of cue lights and tones above the lever. Presses on the inactive lever had no consequences. Mice that showed a pattern of stable responding for 3 consecutive days underwent testing such that each lever press activated the blue laser $(473 \mathrm{~nm})$ leading to activation of $\mathrm{SNr}$ GABA cells simultaneously with the delivery of a food pellet.

Experiment 10: open-field locomotion. To determine whether $\mathrm{SNr}$ GABA neurons are also involved in drug-induced hyperlocomotion, we used optogenetic approaches to selectively stimulate or inhibit these neurons in vGAT-cre mice injected with either cocaine or heroin. Mice with $\mathrm{ChR} 2$ or NpHR expression in the $\mathrm{SNr}$ were first pre-exposed to the 


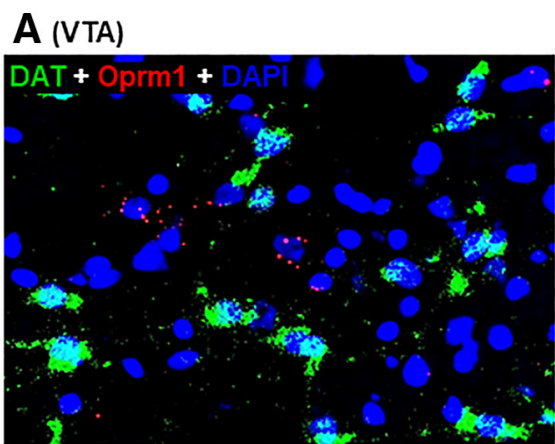

$B$ (SNc)
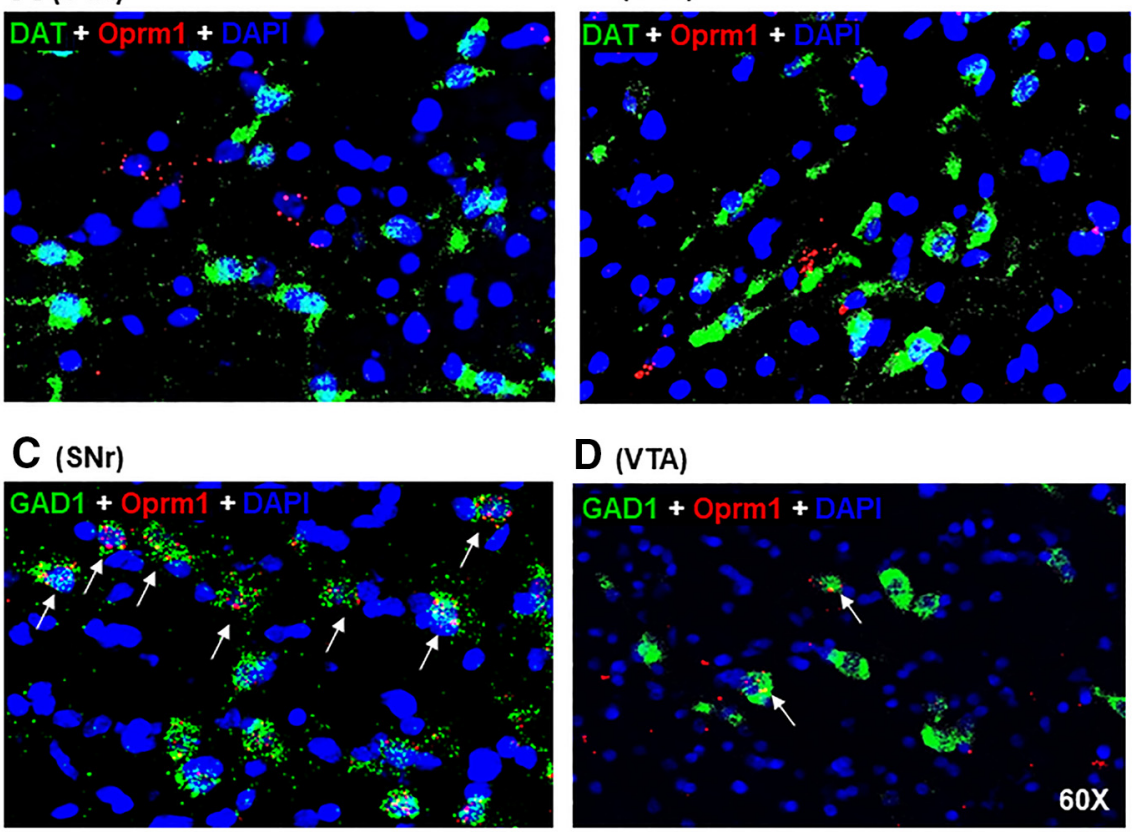

\section{D (VTA)}

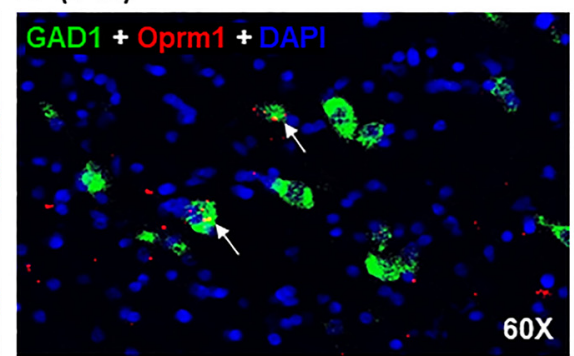

E (RMTg)

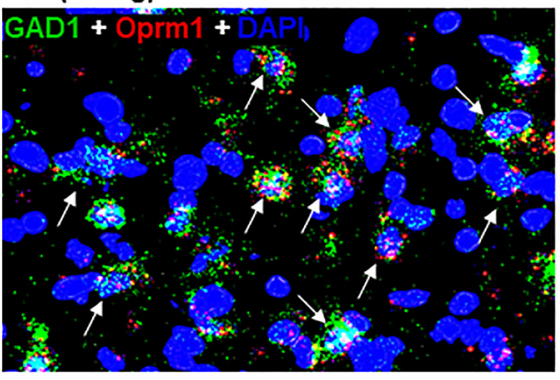

$\mathbf{F}$

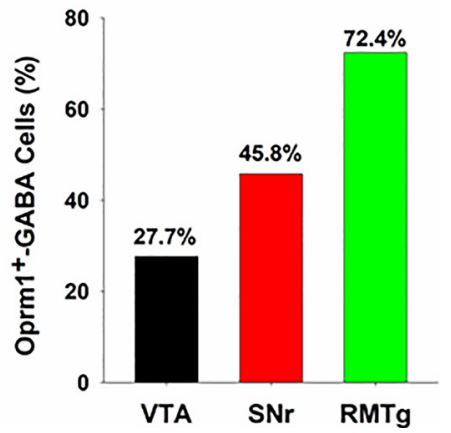

Figure 2. MOR expression in midbrain GABA neurons by RNAscope ISH. $A, B$, Representative images under $60 \times$ magnification, illustrating that MOR (Oprm1) mRNA is not expressed in DAT-positive DA neurons in the VTA (A) and SNc (B). C-E, Representative images under $60 \times$ magnification, illustrating that MOR (Oprm1) mRNA is detected in subpopulations of GAD1-positive GABA neurons in the $\mathrm{SNr}(\boldsymbol{C})$, VTA $(\boldsymbol{D})$, and RMTg $(\boldsymbol{E})$. $\boldsymbol{F}$, Quantitative cell counts illustrating that $\sim 30 \%$ of GABA neurons in the VTA, $\sim 50 \%$ of those in the $\mathrm{SNr}$, and $\sim 70 \%$ those in the tail of the VTA (RMTg) express MORs (150-500 cell counts per region from 3 rats).

locomotor activity chambers. On the test day, during the first $30 \mathrm{~min}$, the baseline locomotor activity was established. Next, animals were injected with either heroin ( $1 \mathrm{mg} / \mathrm{kg}$, i.p.) or cocaine $(10 \mathrm{mg} / \mathrm{kg}$, i.p.), and their locomotor activity was measured with the 473 or $532 \mathrm{~nm}$ laser activated for 15 min to either stimulate or inhibit the SNr GABAergic neurons, respectively, followed by $15 \mathrm{~min}$ locomotor activity with the laser OFF.

Experiment 11: TH and eYFP immunostaining. After completion of the behavioral experiments described below, animals were deeply anesthetized with sodium pentobarbital ( $100 \mathrm{mg} / \mathrm{kg}$, i.p.) and brain were perfused with ice-cold $0.9 \%$ saline followed by $4 \%$ PFA to be then processed for immunohistochemistry assays that allowed us to label VTA/SNc TH or amplify AAV-EYFP expression in the VTA or SNr. Briefly, free-floating coronal sections $(30 \mu \mathrm{m})$ from vGAT-Cre mice with AAV-EFlaChR2-EYFP microinjection were incubated for $1 \mathrm{~h}$ in PB supplemented with $4 \%$ BSA and $0.3 \%$ Triton X-100. Sections were then incubated with cocktails of primary antibodies [rabbit polyclonal anti-TH (Abcam, \#ab152; 1:500) or chicken anti-GFP (Abcam, \#ab13970; 1:500)] overnight at $4^{\circ} \mathrm{C}$. After three rinses (10 min each) in $\mathrm{PB}$, sections were incubated in a cocktail of the corresponding fluorescently labeled secondary antibodies (AlexaFluor-594 goat anti-rabbit and AlexaFluor-488 goat anti-chicken; 1:200; Abcam; \#ab150080; \#ab150173) for $2 \mathrm{~h}$ at room temperature. After rinsing, sections were mounted and coverslipped with DAPI nuclear counterstain (Invitrogen, Fischer Scientific).
Experimental designs and data analysis For self-administration experiments, the numbers of infusions during optogenetic/ pharmacological manipulations were compared to the averaged number of infusions during last three self-administration sessions before the test and at three doses of heroin. These data were analyzed using a three-way ANOVA (treatment $\times$ phase $\times$ heroin dose). For reinstatement experiments, the numbers of the active and inactive lever presses during the last three extinction sessions were averaged and compared to active and lever presses during the reinstatement test, using a three-way ANOVA (treatment $\times$ phase $\times$ lever). For oICSS with ChR2, lever presses were analyzed across six different stimulation frequencies at VTA/SNc regions using a two-way ANOVA (frequency $\times$ region). For oICSS with NpHR, lever presses were analyzed across sessions with a (lever $\times$ session) ANOVA. For RTPP with VTA GABA or DA neurons manipulation, separate one-way ANOVAs with sessions as repeated-measures factor were used. Locomotor activity was analyzed with a three-way ANOVA (time $\times$ phase $\times$ laser). Significant interactions and significant effects were followed by post hoc Dunnett's tests or Bonferroni tests with correction for multiple group comparisons, where appropriate.

\section{Results}

Oprm1 mRNA is expressed in midbrain GABA, not DA, neurons Electrophysiological evidence indicates that functional MORs are expressed in GABA neurons in the brain (Gysling and Wang, 1983; Johnson and North, 1992; Margolis et al., 2014). However, direct morphologic evidence is still lacking. To address this question, we first examined the distributions of GABA neurons in the midbrain. Figure $1 A$ shows GAD67 immunostaining and GAD1- and DAT-mRNA signals, as assessed by IHC and RNAscope ISH, indicating that high densities of GAD1-positive GABAergic neurons are present in the $\mathrm{SNr}$, but less in the VTA and SNc. In contrast, DAT-positive DA neurons are found mainly in the VTA and SNc, but not in SNr.

We then examined the cellular distributions of MORs in DA versus $\mathrm{GABA}$ neurons in the midbrain. We found that Oprm1 mRNA is not colocalized in DAT-positive DA neurons in either the VTA or SNc (Figs. 1B, 2A,B). In contrast, we detected Oprm 1 mRNA in $\sim 50 \%$ of SNr GABAergic neurons and $\sim 30 \%$ of VTA GABAergic neurons (Figs. $1 C, 2 C, D, F$ ). We also examined MOR expression in the tail of the VTA (RMTg) and found that $\sim 72 \%$ of RMTg GABA neurons express Oprm1 mRNA (Fig. 2E,F), in agreement with previous findings using electrophysiological assays (Jhou et al., 2009; Jalabert et al., 2011; Matsui et al., 2014).

Intra-VTA MOR antagonism increases heroin intake in rats To determine the role of MORs in the VTA versus $\mathrm{SNr}$ in opioid reward, we first observed the effects of microinjections of MOR 
A

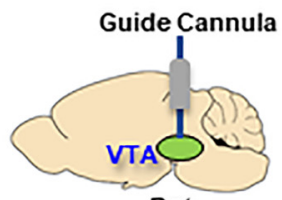

Rat

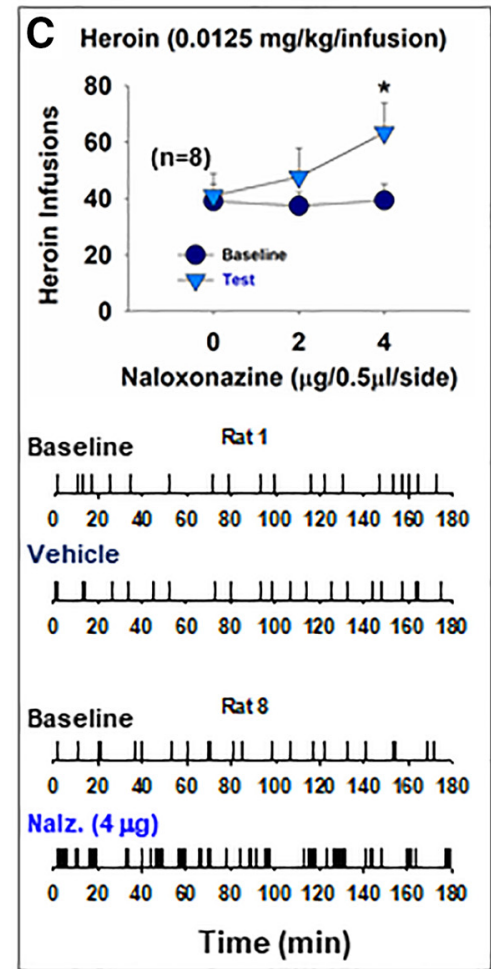

B

\begin{tabular}{|c|c|c|}
\hline Heroin & Heroin & Heroin \\
\hline $5 \mathrm{mg} / \mathrm{kg} /$ infusion) & (0.025 mg/kg/infusion) & (0.0125 mg/kg/infusion) \\
\hline $\begin{array}{l}\text { Naloxonazine } \\
(0,2,4 \mu g / \text { side })\end{array}$ & $\begin{array}{l}\text { Naloxonazine } \\
(0,2,4 \mu \mathrm{g} / \text { side })\end{array}$ & $\begin{array}{c}\text { Naloxonazine } \\
(0,2,4 \mu \mathrm{g} / \mathrm{side})\end{array}$ \\
\hline
\end{tabular}

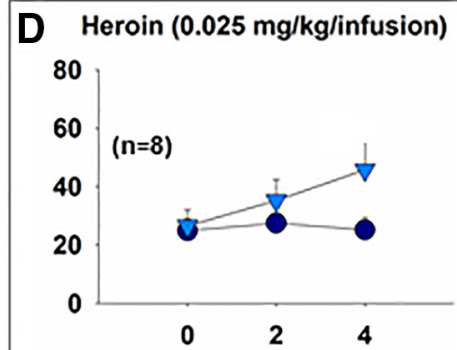

Naloxonazine $(\mu \mathrm{g} / 0.5 \mu \mathrm{l} / \mathrm{side})$

Baseline Rat 5

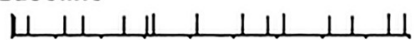

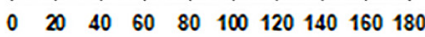

Vehicle

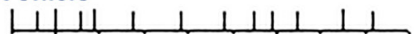

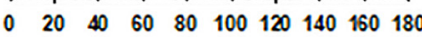

Baseline Rat 9

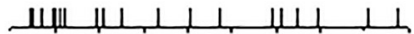
$\begin{array}{llllllllll}0 & 20 & 40 & 60 & 80 & 100 & 120 & 140 & 160 & 180\end{array}$ Nalz. $(4 \mu g)$

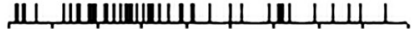

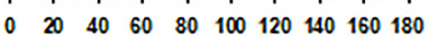
Time (min)

\section{E Heroin (0.05 $\mathrm{mg} / \mathrm{kg} /$ infusion)} 80

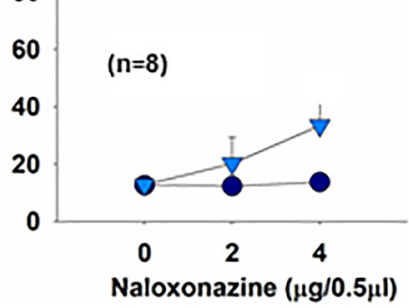

Baseline Rat 1

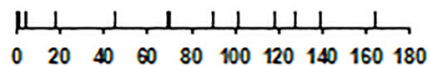
Vehicle

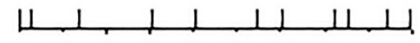

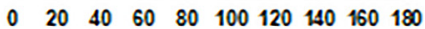

Baseline Rat 3

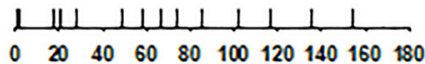
Nalz. $(4 \mu g)$

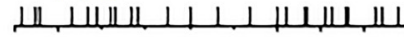

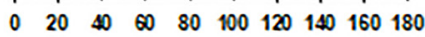
Time (min)
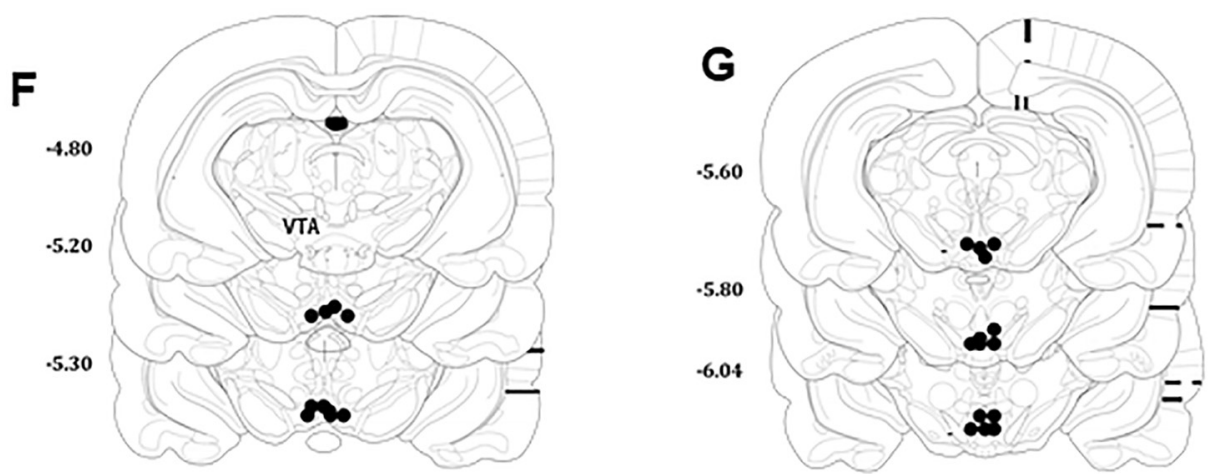

Figure 3. The effects of VTA MOR blockade on heroin self-administration in rats. $A, B$, General experimental procedures. $C-E$, Intra-VTA microinjections of naloxonazine increased the total numbers of heroin infusions. Statistically significant increases in self-administration were observed with the $0.0125 \mathrm{mg} / \mathrm{kg}$ dose of heroin $(\boldsymbol{C}$, but not with the $0.025 \mathrm{mg} / \mathrm{kg} / \mathrm{infusion}(\boldsymbol{D})$ or $0.05 \mathrm{mg} / \mathrm{kg} /$ infusion (E). Bottom panels, Representative event records of heroin infusions during a $3 \mathrm{~h}$ session from individual rats, illustrating higher rates of heroin self-administration and an evenly distributed pattern of heroin self-administration, suggesting a compensatory response in drug intake due to a reduction in heroin reward following MOR blockade ( $n=8$ in each group). $\boldsymbol{F}, \mathbf{G}$, Postexperimental histology illustrating microinjection loci in the VTA in rats. ${ }^{*} p<0.05$ compared to baseline.

antagonists into the VTA or $\mathrm{SNr}$ on heroin self-administration in rats. Figure $3 A, B$ shows the general experimental procedures. Intra-VTA microinjections of the long-lasting MOR antagonist naloxonazine $(0,2,4 \mu \mathrm{g} / 0.5 \mu \mathrm{l} /$ side $)$ produced a significant increase in heroin self-administration maintained by the low dose (Fig. 3C), but not by the high doses (Fig. 3D,E), of heroin. A three-way ANOVA with naloxonazine dose as between-group factor and heroin dose and phase (baseline vs test) as repeatedmeasures factors revealed a main effect of heroin dose $\left(F_{(2,42)}=\right.$ $55.12, p<0.05)$ and significant phase $\times$ naloxonazine interaction $\left(F_{(2,21)}=3.68, p<0.05\right)$. Post hoc tests revealed the significant naloxonazine effect with the $0.0125 \mathrm{mg} / \mathrm{kg} /$ infusion dose of heroin $\left(F_{(2,21)}=4.47, p<0.05\right)$, but not with $0.025 \mathrm{mg} / \mathrm{kg} / \mathrm{infu}-$ sion $\left(F_{(2,21)}=3.04, p=0.06\right)$ or $0.5 \mathrm{mg} / \mathrm{kg} /$ infusion $\left(F_{(2,21)}=2.29\right.$, $p=0.12)$ of heroin. With naloxonazine pretreatment, rats showed increases in heroin self-administration rates and a stable and evenly distributed pattern of responding across different heroin doses (Fig. $3 C-E$ ), suggesting that such an increase in heroin self-administration is most likely a compensatory response to a reduction in heroin reward after naloxonazine pretreatment.

After the completion of the behavioral test, we examined the loci of the tips of the guide cannula for microinjections in the brain. Based on the relative locations of the injector and the tip of the guide cannula (i.e., the injection area is located $1 \mathrm{~mm}$ 
A

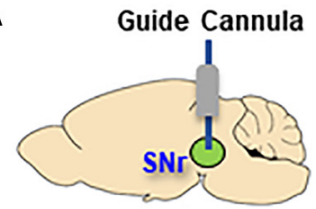

Rat

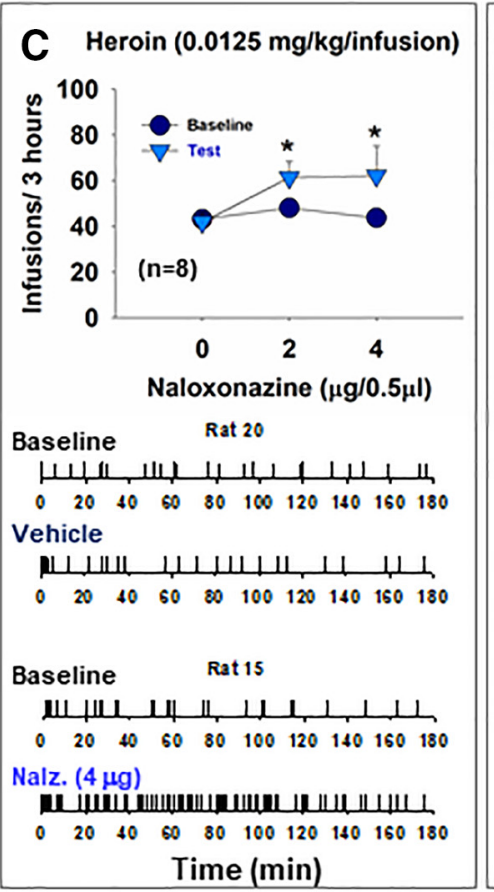

B

\begin{tabular}{|ccc|}
\hline $\begin{array}{c}\text { Heroin } \\
(0.05 \mathrm{mg} / \mathrm{kg} / \text { /infusion })\end{array}$ & $\begin{array}{c}\text { Heroin } \\
(0.025 \mathrm{mg} / \mathrm{kg} / \text { infusion })\end{array}$ & $\begin{array}{c}\text { Heroin } \\
(0.0125 \mathrm{mg} / \mathrm{kg} / \text { infusion })\end{array}$ \\
\hline Naloxonazine & Naloxonazine & Naloxonazine \\
$(0,2,4 \mu \mathrm{g} / \mathrm{side})$ & $(0,2,4 \mu \mathrm{g} / \mathrm{side})$ & $(0,2,4 \mu \mathrm{g} / \mathrm{side})$
\end{tabular}

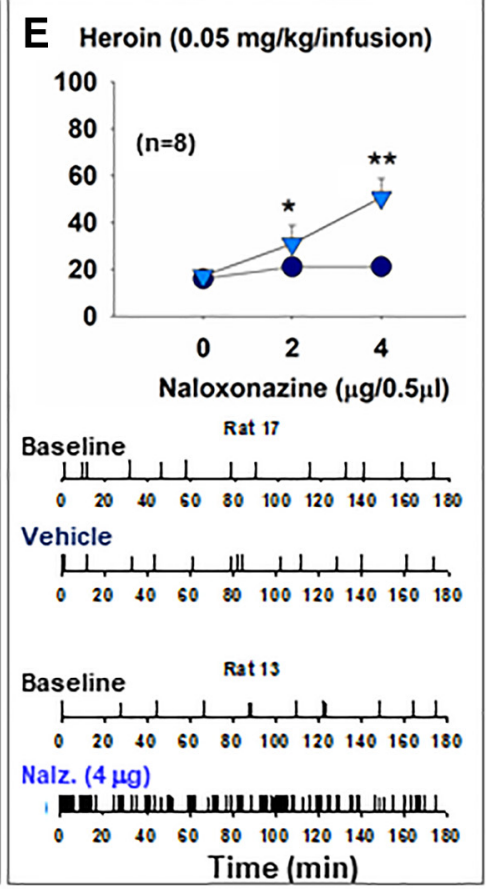

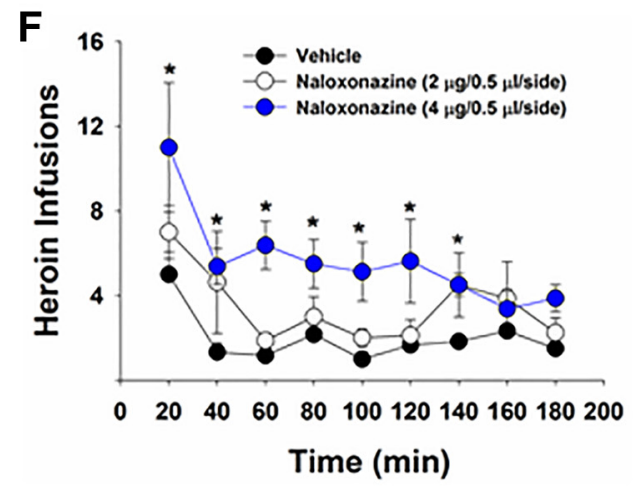

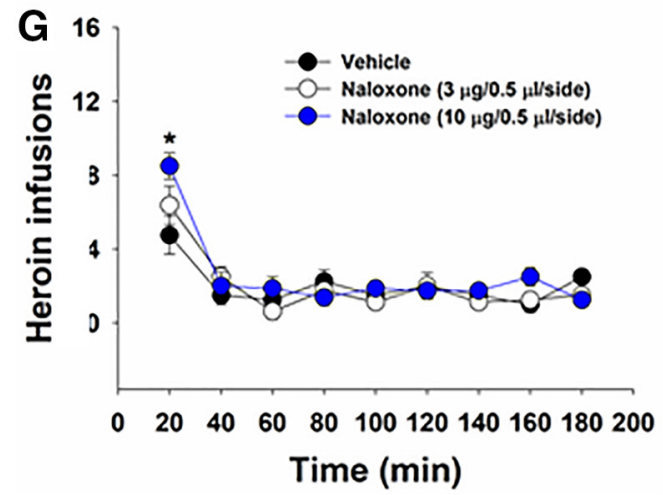

Figure 4. The effects of SNr MOR blockade on heroin self-administration in rats. $\boldsymbol{A}, \boldsymbol{B}$, General experimental procedures. $\boldsymbol{C}-\boldsymbol{E}$, Intra-SNr microinjections of naloxonazine dose-dependently increased heroin self-administration maintained by $0.0125 \mathrm{mg} / \mathrm{kg} /$ infusion $(\boldsymbol{C}), 0.025 \mathrm{mg} / \mathrm{kg} / \mathrm{infusion}(\boldsymbol{D})$, and $0.05 \mathrm{mg} / \mathrm{kg} / \mathrm{infusion}(\boldsymbol{E})$ of heroin. Bottom panels, Representative heroin selfadministration records during a $3 \mathrm{~h}$ session from individual rats, illustrating that microinjections of naloxonazine increased heroin self-administration rates and decreased interinfusion intervals, suggesting a reduction in heroin reward. $\boldsymbol{F}, \mathbf{G}$, The time courses of intravenous heroin self-administration within a 3 -h session after intra-SNr naloxonazine $(0,2,4 \mu \mathrm{g} / \mathrm{side})$ or naloxone $(0,3$, $10 \mu \mathrm{g} / \mathrm{side}$ ) pretreatment, illustrating that naloxonazine's action is long-lasting, whereas naloxone's action is not. ${ }^{*} p<0.05,{ }^{* *} p<0.01$ as compared to baseline ( $n=8$ in each group).

below the tip of a cannula) and the spread area with $0.5 \mu$ l blue dye in the VTA as reported previously (Xi et al., 2004), we verified that all the microinjections were located within the VTA, as shown in Figure $3 F, G$. These findings suggest that MORs in the VTA play a limited role in opioid reward.

Intra-SNr MOR antagonism increases heroin intake in rats We then observed the effects of intra-SNr microinjections of naloxonazine on heroin self-administration in rats (Fig. 4A,B). We found that intra-SNr microinjections of naloxonazine $(0,2$, $4 \mu \mathrm{g} / 0.5 \mu \mathrm{l} /$ side) dose-dependently increased heroin self-administration. The naloxonazine-induced increases in heroin intake were observed across three heroin doses (Fig. 4C-E). A threeway ANOVA with naloxonazine dose as between-group factor and heroin dose and phase (baseline vs test) as repeated-measures factors revealed a significant naloxonazine $\times$ heroin $\times$ phase interaction $\left(F_{(4,40)}=11.48, p<0.001\right)$. Post hoc tests revealed the naloxonazine effect on the $0.0125 \mathrm{mg} / \mathrm{kg} /$ infusion dose of heroin (Fig. $4 C ; F_{(2,20)}=4.15, p<0.05$ ), $0.025 \mathrm{mg} / \mathrm{kg} /$ infusion (Fig. $4 D ; F_{(2,20)}=6.06, p<0.01$ ), and $0.05 \mathrm{mg} / \mathrm{kg} / \mathrm{infu}-$ sion dose of heroin (Fig. $4 E ; F_{(2,20)}=6.07, p<0.01$ ). The effects of naloxonazine on heroin self-administration were long lasting (up to $2 \mathrm{~h}$ ), as indicated in Figure $4 F$.

We also observed the effects of intra-SNr microinjections of naloxone, another more commonly used MOR antagonist, on 


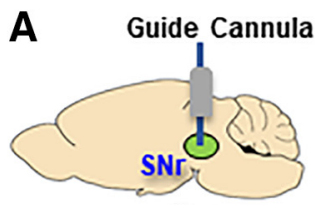

Rat

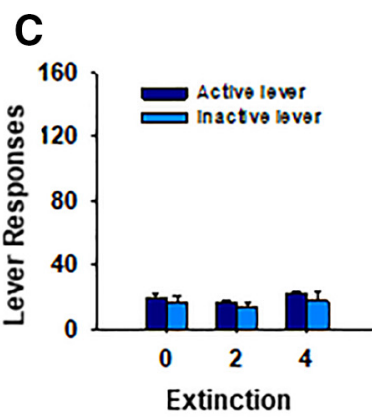

E

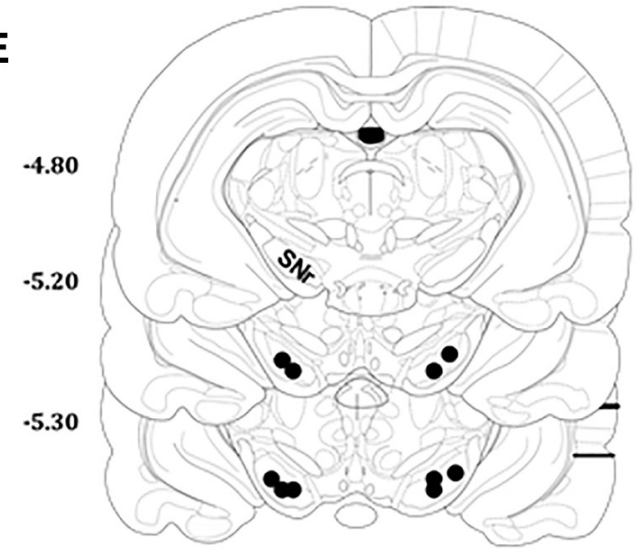

B

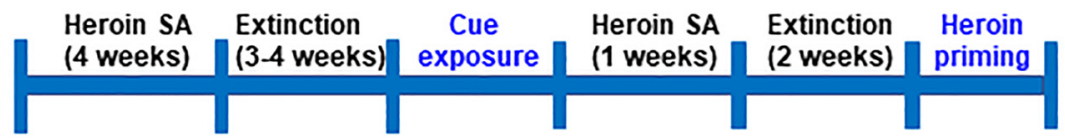

D
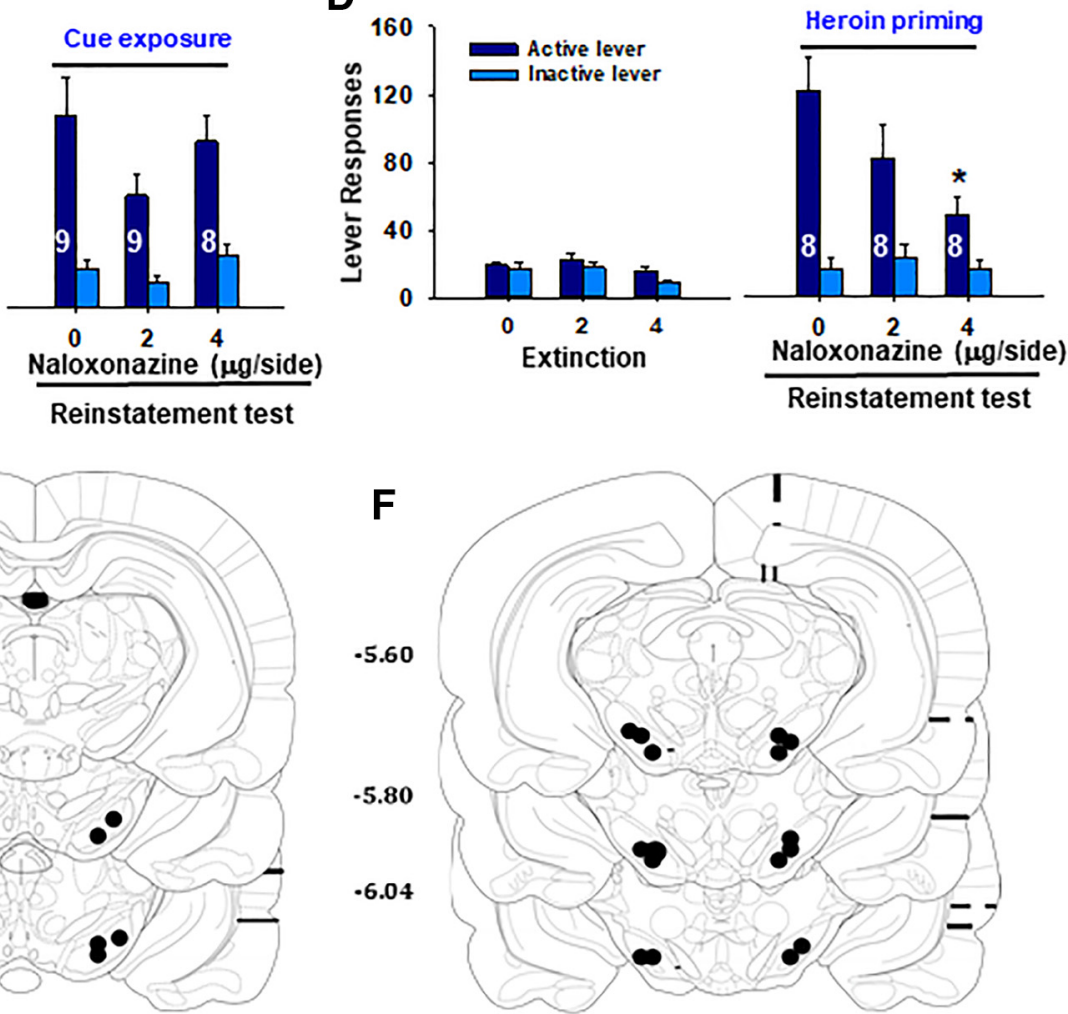

Figure 5. The effects of SNr MOR blockade on reinstatement of heroin-seeking in rats. $\boldsymbol{A}, \boldsymbol{B}$, General experimental procedures. $\boldsymbol{C}$, Lever responding on the active and inactive levers during the last session of extinction and cue-induced reinstatement tests. Intra-SNr microinjections of naloxonazine failed to alter cue-induced reinstatement of drug-seeking. $\boldsymbol{D}$, Lever responding on the active and inactive levers during the last extinction and reinstatement sessions. Intra-SNr microinjections of naloxonazine dose-dependently inhibited $1 \mathrm{mg} / \mathrm{kg}$ (i.p.) heroin-primed reinstatement of drug-seeking. $\boldsymbol{E}, \boldsymbol{F}$, Postexperimental histologic examination results, illustrating the locations of the intra-SNr microinjections. ${ }^{*} p<0.05$ compared with the vehicle control group ( $n=8$ or 9 per group).

heroin self-administration in rats. Bilateral microinjections of naloxone $(0,3,10 \mu \mathrm{g} / / 0.5 \mu \mathrm{l} /$ side $)$ into the $\mathrm{SNr}$ did not significantly alter the total numbers of heroin infusions earned during a $3 \mathrm{~h}$ test session. By examining the time course of heroin self-administration, we found that naloxone dose-dependently increased heroin self-administration in the first $20 \mathrm{~min}$ of the self-administration session (Fig. 4G), suggesting that its effect was short lasting.

\section{Intra-SNr MOR antagonism reduces heroin-primed} reinstatement

Next, we examined whether MORs in the $\mathrm{SNr}$ are involved in relapse to heroin-seeking in rats. In this experiment, we first trained rats for heroin self-administration paired with a complex light/tone cue, followed by extinction of operant responding without the cues previously paired with heroin infusions (Fig. $5 A, B)$. Then the rats were first tested in a cue-induced reinstatement procedure (Wang et al., 2015). Reexposure to the heroinassociated cues reinstated drug-seeking, which was not altered by intra-SNr microinjections of naloxonazine (Fig. 5C). A threeway ANOVA with naloxonazine dose as between-group factor and lever and phase (extinction vs reinstatement) as repeated- measures factors revealed a significant lever $\times$ phase interaction $\left(F_{(2,23)}=1.55, p<0.001\right)$, but not naloxonazine $\times$ lever $\times$ phase interaction. Post hoc test revealed a significant cue-induced reinstatement effect (Fig. 5C; $F_{(1,23)}=55.35, p<0.001$ ).

Rats then continued daily heroin self-administration for $7 \mathrm{~d}$ and then followed by extinction training until the extinction criteria were met $(<20$ lever presses for three consecutive sessions). Heroin priming $(1 \mathrm{mg} / \mathrm{kg}$, i.p.) produced robust reinstatement of drug-seeking, which was dose-dependently attenuated by intra$\mathrm{SNr}$ microinjections of naloxonazine (Fig. 5D). A three-way ANOVA with naloxonazine dose as between-group and lever and phase as repeated-measures factors revealed a significant naloxonazine $\times$ lever $\times$ phase interaction $\left(F_{(2,21)}=9.03, p<\right.$ 0.01). Post hoc test revealed a significant naloxonazine effect on reinstatement $\left(F_{(2,21)}=8.33, p<0.001\right)$. After the completion of the behavioral test, we verified the microinjection loci histologically. All the microinjections were located within the SNr, as shown in Figure 5E,F.

\section{Optogenetic activation of VTA DA neurons is rewarding}

There is evidence supporting the role of DA neurons in opioid reward, as described above. But some studies refute the DA 
A

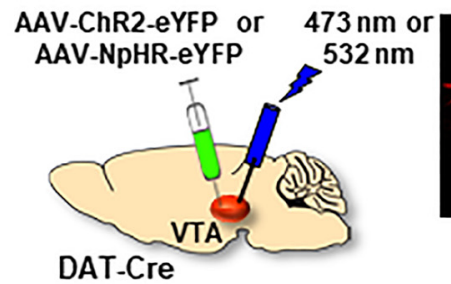

E (olcss)

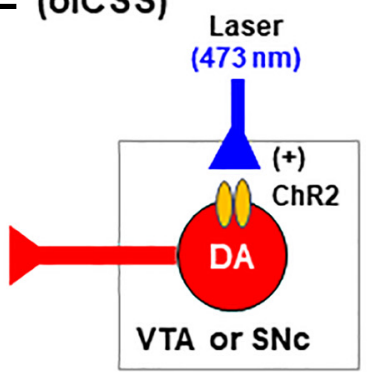

B

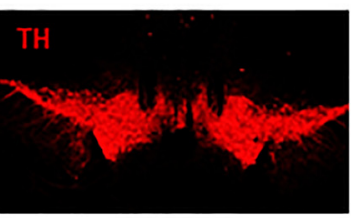

F (olcss)

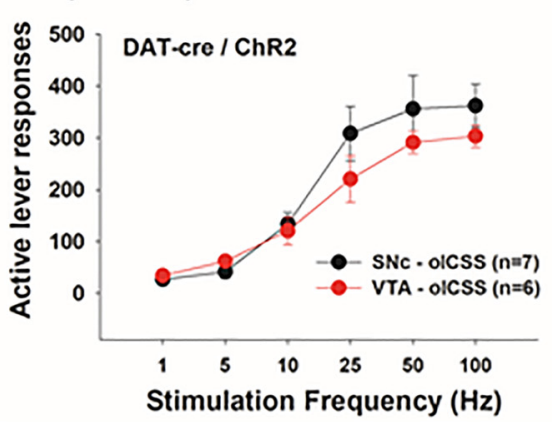

D
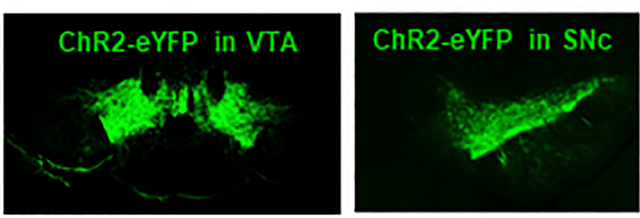

G (Real-Iime Place Preference)

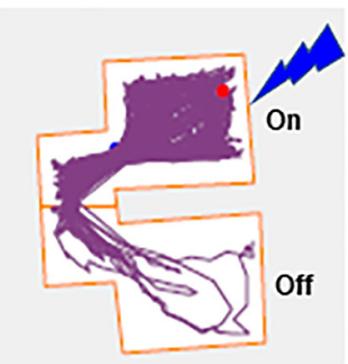

ChR2 in VTA DA neurons

\section{H (RTPP)}
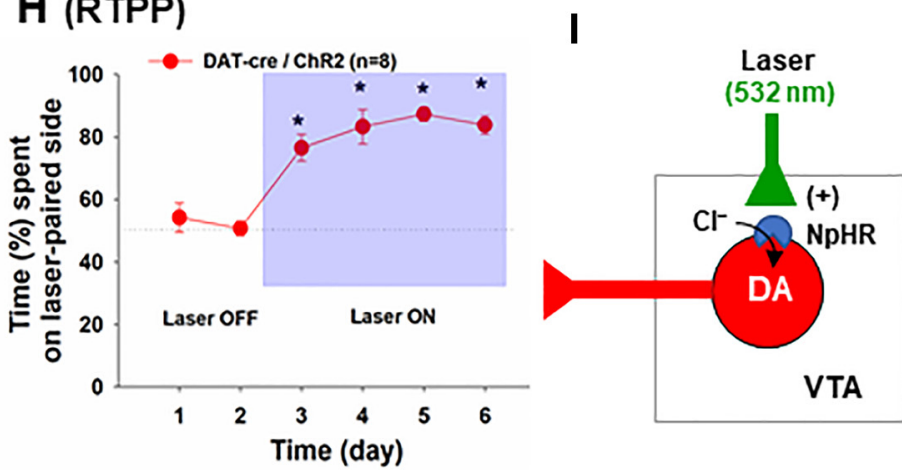

\section{$\mathbf{J}$ (Heroin SA + Laser)}

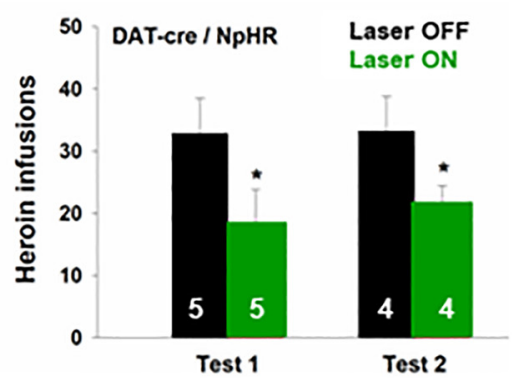

K (Representative heroin SA records)
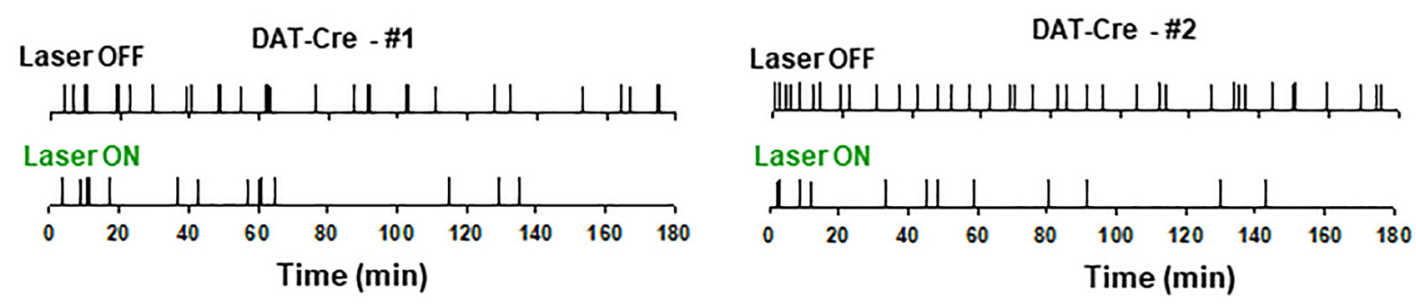

Figure 6. The effects of optogenetic manipulations of VTA DA neurons on heroin self-administration in DAT-cre mice. $\boldsymbol{A}$, General experimental methods. $\boldsymbol{B}$-D, Representative images showing AAV-ChR2-eYFP expression in the VTA or SNc in DAT-cre mice. $E, F$, Optogenetic activation of DA neurons in the VTA or SNc is rewarding, as assessed by stimulation frequency-dependent olCSS in DAT-cre mice ( $n=6$ or 7 per group). $\mathbf{G}$, Representative trace recording, indicating that DAT-cre mice with ChR2 expression in VTA DA neurons spent more time in the laser-paired compartment. $\boldsymbol{H}$, Experimental results of optical RTPP across six sessions indicate that activation of VTA DA neurons is rewarding $(n=8)$. $\boldsymbol{I}, \boldsymbol{J}$, Response-contingent optical inhibition of VTA DA neurons caused a significant reduction in heroin self-administration in DAT-cre mice after stable intravenous heroin self-administration was achieved $(n=5)$. $\boldsymbol{K}$, Representative heroin self-administration records from 2 DAT-cre mice with NpHR expression on VTA DA neurons, indicating that response-contingent optical inhibition of VTA DA neurons inhibited heroin self-administration. Animals displayed an extinction-like pattern of self-administration in the presence of laser stimulation, initial higher rates of responding followed by a progressive reduction in drug taking. ${ }^{*} p<0.05$ compared to Laser Off conditions.

disinhibition hypothesis. To further address this issue, we examined whether optogenetic stimulation of DA neurons in the VTA or $\mathrm{SNc}$ is rewarding. Figure $6 \mathrm{~A}$ shows the general experimental procedures. Figure $6 B-D$ shows representative images of TH immunostaining and ChR2-eYFP expression in the VTA and SNc, respectively. We first trained DAT-cre mice to press lever for optical self-stimulation of VTA DA neurons or SNc DA neurons (Fig. $6 E$ ). We found that optogenetic activation of DA neurons in either the VTA or SNc is rewarding. Both groups of mice displayed classical sigmoid-shape stimulation frequency-dependent oICSS (Fig. $6 F$ ). We then used the optical RTPP procedure to confirm the above finding. Figure $6 G$ shows a representative tracing record, illustrating that the animal spent more time in the RTPP chamber paired with the laser stimulation of VTA DA neurons. Optogenetic stimulation of VTA DA neurons produced robust place preference in DAT-cre mice (Fig. 6H; one-way ANOVA with session as a repeated-measures factor, $F_{(5,35)}=$ 29.79, $p<0.001)$. 


\section{Optogenetic inhibition of VTA DA neurons inhibits heroin self-administration}

We then hypothesized that, if opioid reward was mediated by disinhibition of VTA DA neurons, optogenetic inhibition of VTA DA neurons should inhibit heroin self-administration. To test this hypothesis, we first trained DAT-cre mice to self-administer heroin until stable responding was achieved. On the test day, each active lever responding led to a delivery of a heroin infusion and optical stimulation to inhibit VTA DA neurons. In DAT-cre mice with VTA NpHR expression in VTA DA neurons (Fig. 6I), response-contingent optogenetic inhibition of DA neurons $(532 \mathrm{~nm}, 10 \mathrm{~mW} /$ side, constant, $20 \mathrm{~s})$ caused a significant reduction in intravenous heroin self-administration (Fig. 6J). A two-way ANOVA with Laser (On/Off) and test as repeatedmeasures factors revealed a significant Laser effect $\left(F_{(1,4)}=15.85\right.$, $p<0.05)$. Figure $6 K$ shows the patterns of heroin self-administration in the absence or presence of laser stimulation. The animals displayed an extinction-like pattern of heroin selfadministration - an initial higher rate of responding followed by a progressive reduction in drug taking, suggesting that inactivation of VTA DA neurons substantially reduced opioid reward, resulting in the cessation of responding for heroin.

\section{Optogenetic activation of VTA GABA neurons does not alter heroin self-administration}

As stated above, opioid reward has been thought to be mediated by opioid-induced inhibition of VTA GABA neurons that leads to disinhibition of VTA DA neurons. If this is true, optical activation of VTA GABA neurons should inhibit heroin self-administration. To test this hypothesis, vGAT-cre mice with ChR2 expression in VTA GABA neurons were first trained for heroin self-administration (Fig. 7A,B). After stable self-administration was achieved, each active lever responding led to a delivery of a heroin infusion and optical stimulation to activate VTA GABA neurons (Fig. $7 B, C$ ). Unexpectedly, response-contingent optical activation of VTA GABA neurons failed to alter heroin selfadministration maintained by three different doses of heroin (Fig. 7D). Separate one-way ANOVAs with session as a repeatedmeasures factor did not reveal significant session main effects in the presence or absence of the laser stimulation (for $0.1 \mathrm{mg} / \mathrm{kg} /$ infusion dose of heroin, the last three sessions: $F_{(2,12)}=0.02, p>0.05$; for $0.05 \mathrm{mg} / \mathrm{kg} /$ infusion dose of heroin: $F_{(4,24)}=1.32, p>0.05$; for $0.025 \mathrm{mg} / \mathrm{kg} /$ infusion dose of heroin: $\left.F_{(4,24)}=0.96, p>0.05\right)$. To determine whether optogenetic stimulation of VTA GABA neurons, which failed to alter heroin self-administration, can induce any behavioral changes in vGAT-cre mice, we examined place preference in response to the same laser stimulation in a RTPP paradigm. We found that optical stimulation of VTA GABA neurons produced robust place aversion in vGAT-cre mice (Fig. 7E). A oneway ANOVA with session as a repeated-measures factor revealed a significant session main effect (Fig. $7 E ; F_{(5,45)}=17.22, p<0.001$ ). Post hoc test for multiple group comparisons revealed a significant reduction in the time spent in the laser-paired chamber compared to the time in the chamber without laser stimulation. To confirm this unexpected finding, an additional group of vGAT-cre mice with ChR2 expression in VTA GABA neurons were initially trained to self-administer cocaine $(0.5 \mathrm{mg} / \mathrm{kg} /$ infusion $)$ until stable selfadministration was achieved. We found that response-contingent optical activation of VTA GABA neurons significantly inhibited cocaine self-administration (Fig. $7 F ; F_{(2,10)}=6.37, p<0.05$ ). Figure $7 G$ shows the patterns of cocaine self-administration, illustrating that optical activation of VTA GABA neurons substantially reduced cocaine reward as assessed by the extinction-like pattern of selfadministration as described above. These findings suggest that VTA GABA neurons may play a more important role in cocaine reward than opioid reward. This is in line with our findings that the percent of VTA GABA neurons expressing MOR mRNA is low and intraVTA microinjections of naloxonazine reduce self-administration of the low, but not high, doses of heroin.

\section{Optical stimulation of SNr GABA neurons decreases heroin reward}

Next, we examined whether optical stimulation of SNr GABA neurons would decrease heroin self-administration. Figure $8 A-C$ shows the general experimental procedures and representative images, illustrating AAV-ChR2-eYFP expression in SNr GABA neurons. In this experiment, we first trained vGAT-cre mice for intravenous heroin self-administration. During the test session, each active lever response led to a delivery of a heroin infusion, presentation of the light/tone cue and optical stimulation of $\mathrm{SNr}$ GABA neurons. Figure $8 D$ shows representative event records of heroin self-administration in the presence or absence of optical stimulation. Response-contingent optical activation of $\mathrm{SNr}$ GABA neurons caused a significant increase in heroin selfadministration rates and a reduction in interinfusion intervals. With optical stimulation, across different heroin doses, mice showed increases in heroin self-administration rates but still maintained a stable and evenly distributed pattern of responding (Fig. 8D), similar to the pattern observed when heroin doses were reduced (Fig. $8 E$, Laser Off conditions), suggesting a reduction in heroin reward after stimulation of SNr GABA neurons. Figure $8 E$ shows the averaged heroin dose-response curves, illustrating that optical activation of SNr GABA neurons significantly shifted a heroin dose-response curve upward. A two-way ANOVA with heroin and Laser (On/Off) as repeated-measures factors revealed a significant heroin dose main effect $\left(F_{(2,14)}=\right.$ $16.45, p<0.001)$ and laser main effect $\left(F_{(1,7)}=5.99, p<0.01\right)$. We also examined the effects of optogenetic stimulation of $\mathrm{SNr}$ GABA neurons on nondrug reinforcement-food self-administration (Fig. $8 F$ ). We found that that response-contingent activation of SNr GABA neurons had no effect on food self-administration (Fig. 8F). These findings suggest that ChR2-induced stimulation of SNr GABA neurons selectively reduced the rewarding effects of heroin, in a similar way as pharmacological blockade of $\mathrm{SNr}$ MORs did.

\section{Optical stimulation of SNr GABA neurons attenuates heroin-primed reinstatement}

We also explored the role of SNr GABA neurons in relapse to opioid-seeking. After completion of the heroin self-administration experiments, the same group of mice underwent extinction training, during which active lever presses were not reinforced by heroin infusions or drug cues. During the reinstatement test, each lever response led to reexposure of drug cues and optical activation of SNr GABA neurons. In the absence of optical stimulation (laser Off), heroin priming ( $1 \mathrm{mg} / \mathrm{kg}$, i.p.) caused robust reinstatement of drug-seeking, which was decreased by optical activation of SNr GABA neurons in vGAT-cre mice (Fig. 8G). A two-way ANOVA with phase and lever as repeated-measures factors revealed a significant phase $\times$ lever interaction $\left(F_{(2,10)}=\right.$ 20.96, $p<0.001$; post hoc test for Laser On/Off effect: $F_{(1,5)}=$ $16.42 ; p<0.01$ ). 
A

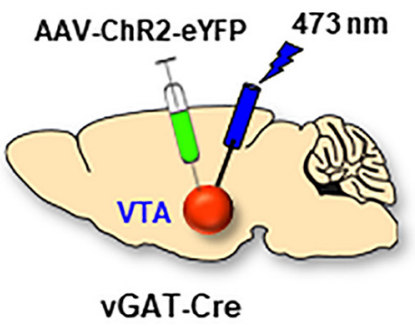

B

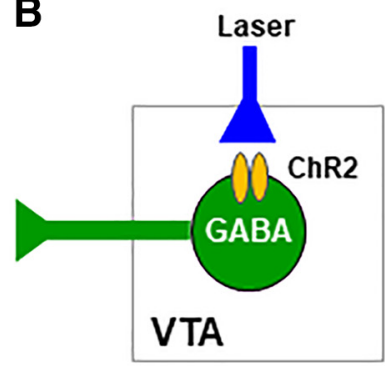

C

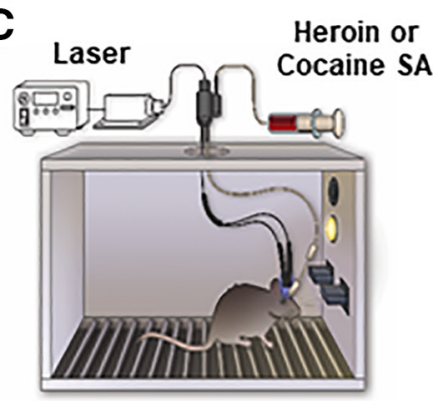

D

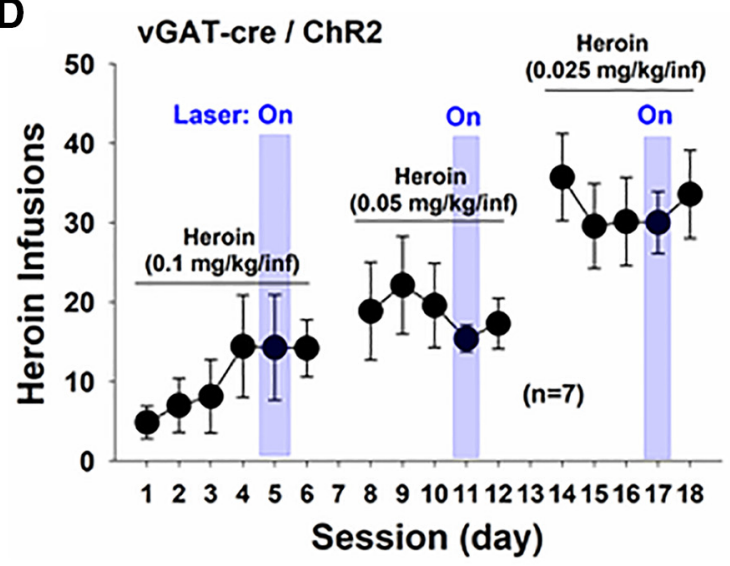

E

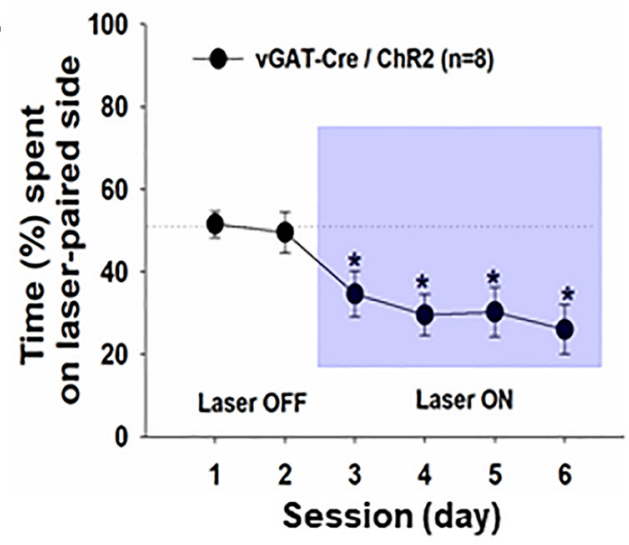

F

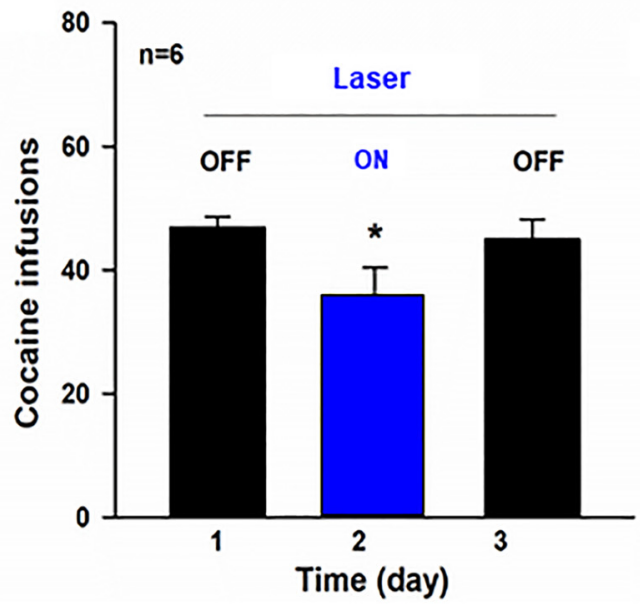

G

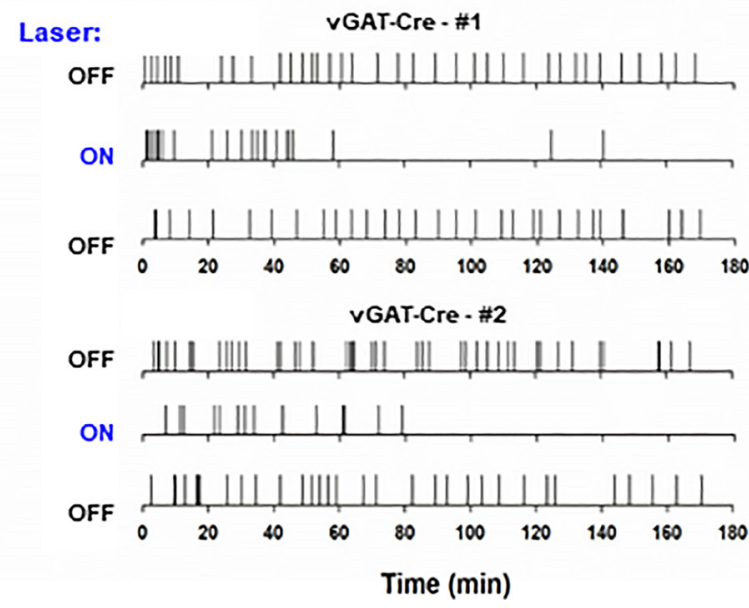

Figure 7. The effects of optogenetic modulation of VTA GABA neurons on heroin or cocaine self-administration. $\boldsymbol{A}-\boldsymbol{C}$, General experimental procedures. $\boldsymbol{D}$, Response-contingent optical activation of VTA GABA neurons failed to alter intravenous heroin self-administration in VGAT-cre mice $(n=7)$ after stable self-administration was achieved. $\boldsymbol{E}$, Optical activation of VTA GABA neurons is aversive, as assessed by RTPP. vGAT-cre mice with ChR2 expression in VTA GABA neurons $(n=10)$ spent less time in laser-paired compartment. $\boldsymbol{F}$, Response-contingent optical activation of VTA GABA neurons inhibited intravenous cocaine self-administration in vGAT-cre mice. $G$, Representative cocaine self-administration records from 2 vGAT-cre mice, indicating that response-contingent optical activation of VTA GABA neurons inhibited cocaine self-administration. ${ }^{*} p<0.05$ as compared to the baseline or Laser Off conditions.

Optogenetic inhibition of SNr GABA neurons is rewarding We also examined whether optical activation or inhibition of $\mathrm{SNr}$ GABA neurons is rewarding or aversive in a way similar to manipulation of VTA GABA neurons. In this experiment, three groups of vGAT-cre mice received intra-SNr microinjections of AAV-ChR2, AAV-NpHR, or AAV-eYFP, respectively (Fig. 9A, $B)$. In contrast to the finding in the VTA, optogenetic activation of $\mathrm{SNr}$ GABA neurons was neither rewarding nor aversive, as assessed by RTPP (Fig. 9C,D). In contrast, optogenetic inhibition of $\mathrm{SNr}$ GABA neurons was rewarding (Fig. 9C,D). A two-way
ANOVA with session as repeated-measures factor and AAV expression as between-group factor revealed a significant session $\times$ group interaction $\left(F_{(10,90)}=3.16, p<0.01\right.$; post hoc test for the AAV NpHR effect: $\left.F_{(5,40)}=13.98, p<0.001\right)$. Mice transfected with NpHR spent $\sim 65 \%$ of the time spent in the laser-paired compartment (Fig. 9C,D), whereas those with the ChR2 or eYFP expression in SNr GABA neurons spent similar amounts of time in both compartments.

To confirm the above findings, we examined whether optogenetic inhibition of SNr GABA neurons can maintain oICSS 

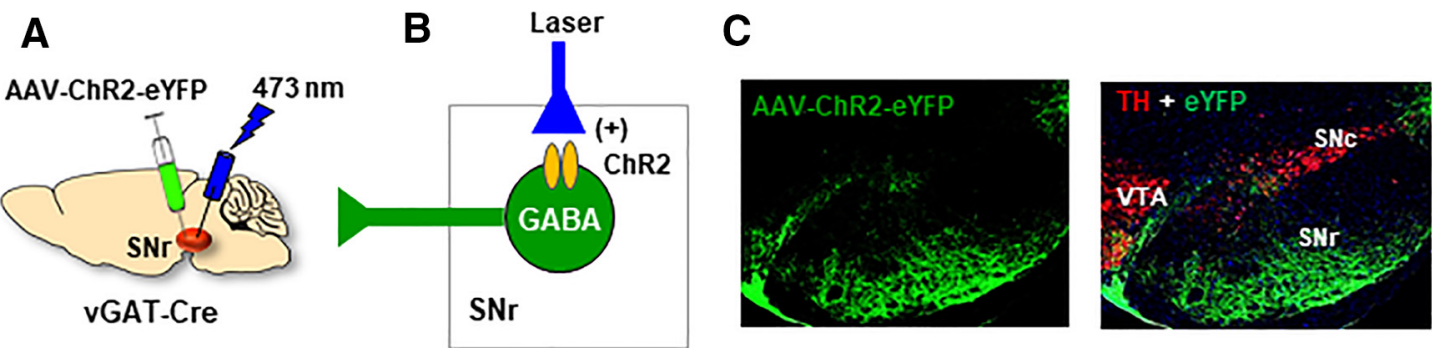

D (Representative heroin self-administration)
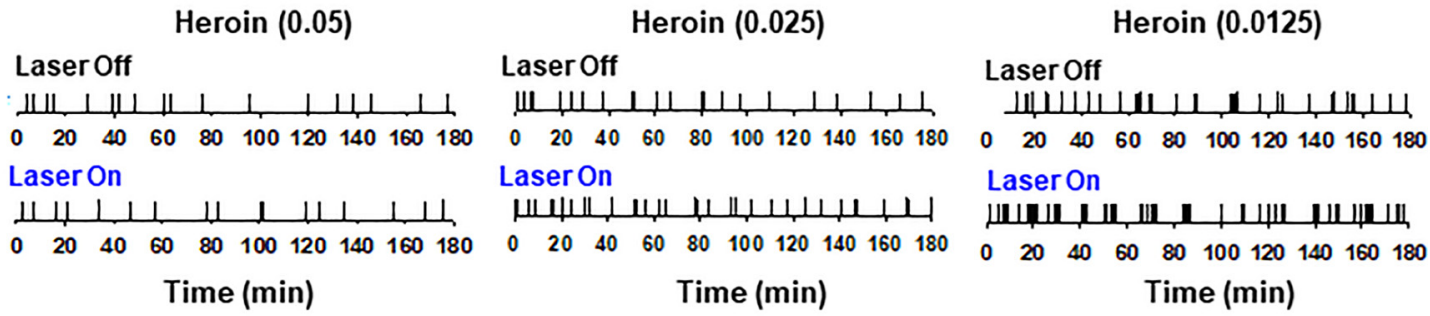

\section{E (Heroin self-administration)}

F (Food self-administration)

\section{G(Heroin-induced reinstatement)}
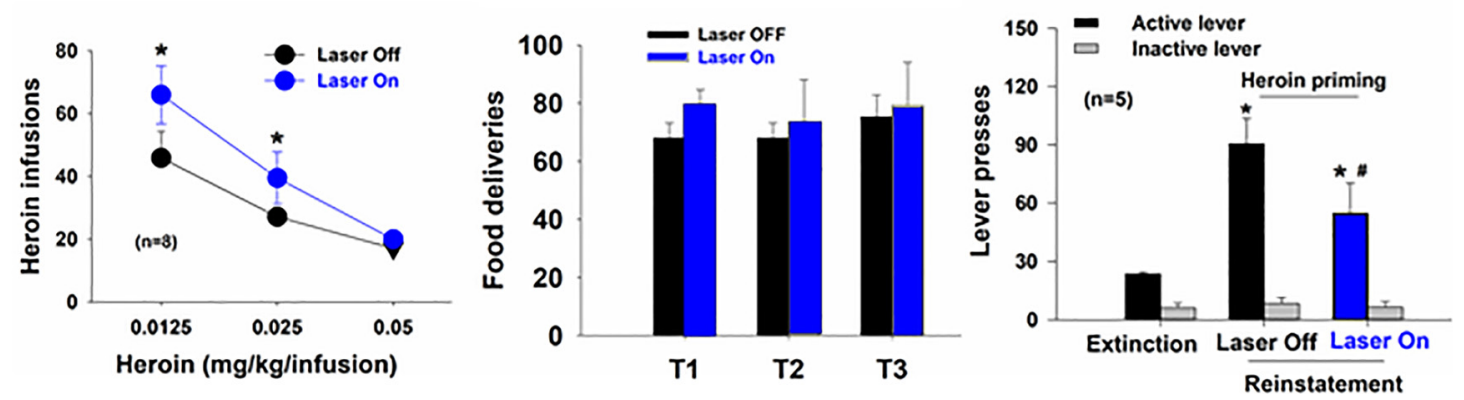

Figure 8. Optical activation of SNr GABA neurons inhibits heroin reward and heroin-primed reinstatement in vGAT-cre mice. $\boldsymbol{A}, \boldsymbol{B}$, The general experimental procedures. $\boldsymbol{C}$, Representative images showing AAV-ChR2-eYFP expression in SNr GABA neurons. $\boldsymbol{D}$, Representative heroin self-administration records in the presence or absence of optical stimulation of SNr GABA neurons. $\boldsymbol{E}$, Response-contingent optical activation of SNr GABA neurons potentiated heroin self-administration and shifted the heroin dose-response curve upward in vGAT-cre mice $(n=8)$. $\boldsymbol{F}$, Response-contingent optical activation of SNr GABA neurons failed to alter food self-administration. G, Response-contingent optical activation of SNr GABA neurons inhibited heroin-primed reinstatement of drug-seeking behavior in mice with a history of heroin self-administration. ${ }^{*} p<0.05$ as compared to the Laser off condition $(\boldsymbol{E})$ or Extinction $(\boldsymbol{G}){ }^{\#} p<0.05$ as compared to Laser Off conditions (G).

(Fig. 9E). In this experiment, vGAT-cre mice with NpHR or eYFP expression in SNr GABA neurons were trained to press a lever for oICSS. Figure $9 F$ shows representative active lever responses observed within a $2 \mathrm{~h}$ session, illustrating robust response-contingent active lever presses in vGAT-Cre mice with NpHR expression, but not in those with the control eYFP expression (Fig. 9F,G). A two-way ANOVA with AAV expression as between-group factor and session as repeated-measures factor revealed a significant AAV group $\times$ session interaction (Fig. $9 G$; $F_{(11,143)}=2.71, p<0.01$; post hoc test for the AAV-NpHR group effect: $\left.F_{(1,13)}=15.83, p<0.01\right)$.

Activation of SNr GABA neurons attenuates heroin- or cocaine-induced hyperlocomotion

Last, we examined the effects of SNr GABA neuron activation (Fig. 10A) or inhibition (Fig. 10D) on basal and heroin (or cocaine)-induced locomotion. Activation of SNr GABA neurons alone decreased (Fig. 10B, laser alone: $F_{(2,8)}=30.84, p<0.001$; Fig. $\left.10 C, F_{(2,8)}=5.08, p<0.05\right)$, whereas optical inhibition of $\mathrm{SNr}$ GABA neurons potentiated open-field locomotion (Fig. $10 E$, laser alone: $F_{(2,8)}=28.16, p<0.001$; Fig. $10 F, F_{(2,8)}=5.08$, $p<0.01$ as compared to the baseline). Systemic administration of heroin $(1 \mathrm{mg} / \mathrm{kg}$, i.p.) significantly increased locomotor activity (Fig. $10 B, F_{(2,8)}=6.73, p<0.05$; Fig. $10 E, F_{(2,8)}=11.23$, $p<0.01$ as compared to the baseline), which was reduced by optical stimulation of SNr GABA neurons in vGAT-cre mice (with ChR2 expression in SNr GABA neurons) (Fig. 10B; $F_{(2,8)}=$ 21.81, $p<0.001$ ), but not by optical inhibition of SNr GABA neurons in mice with NpHR expression in SNr GABA neurons (Fig. 10E). Similarly, optical stimulation of SNr GABA neurons also reduced cocaine $(10 \mathrm{mg} / \mathrm{kg}$, i.p.)-induced hyperlocomotion (Fig. $\left.10 C ; F_{(4,16)}=5.68, p<0.05\right)$, whereas optical inhibition of SNr GABA neurons failed to alter locomotor response to cocaine (Fig. 10F; $F_{(2,8)}=1.67, p>0.05$ ).

Verification of AAV-ChR2-eYFP expression in the brain After the completion of the above behavioral tests, we examined the locations of virus expression or fiber tips in the midbrain. Since the virus injections were done via a 30 -gauge removable injector and the implanted optical fibers used for optical stimulation are extremely thin $(20 \mu \mathrm{m})$, it is technically very difficult to find the injector or fiber trace in the postmortem brain tissues. Alternatively, we examined the eYFP expression after intra-VTA or intra-SNr virus injections. Figure $6 B-D$ shows 


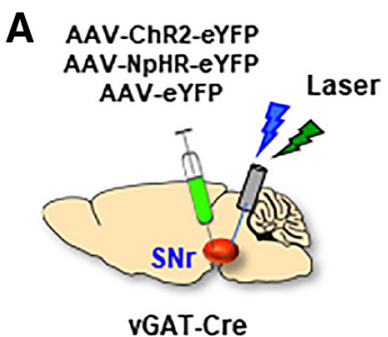

B

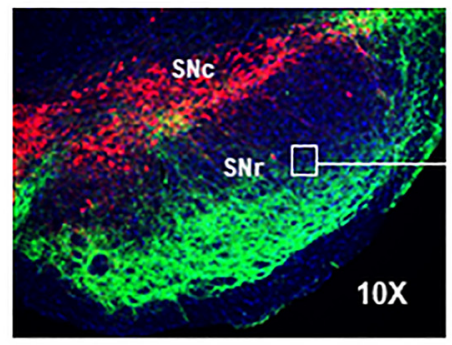

$\mathrm{TH}+\mathrm{eYFP}+\mathrm{DAPI}$

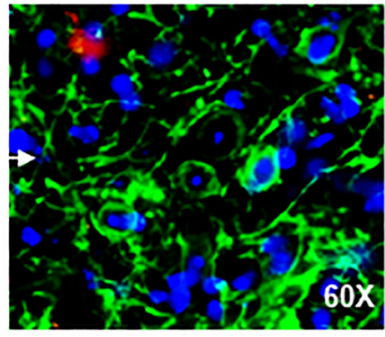

\section{C (Representative optical RTPP)}

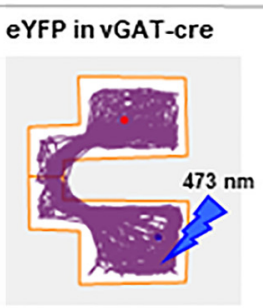

$\mathbf{E}$

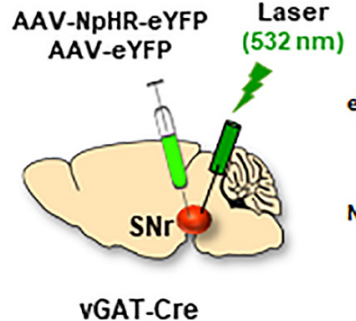

F (Representative ICSS)

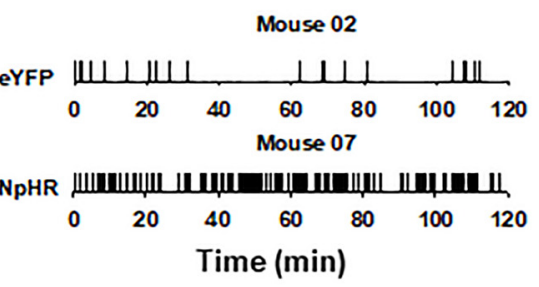

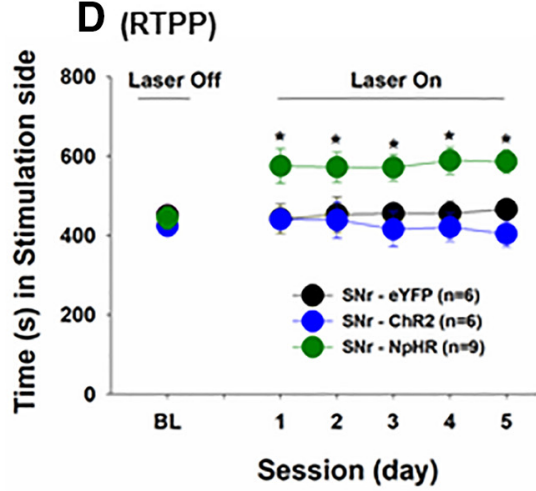

G (oICSS)

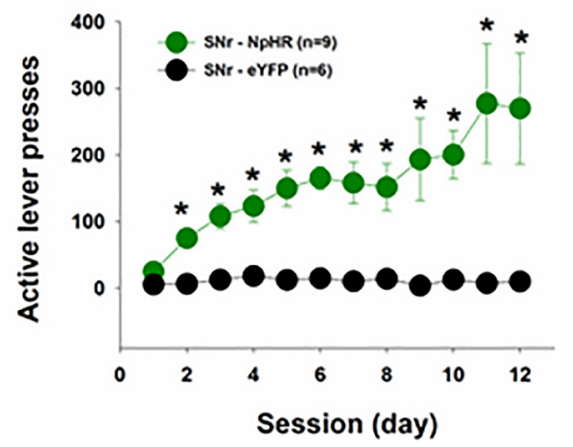

Figure 9. Optical inhibition of SNr GABA neurons is rewarding in VGAT-cre mice. $\boldsymbol{A}$, General experimental procedures. $\boldsymbol{B}$, Representative images, illustrating AAV-NpHR-eYFP expression in SNr GABA neurons and their projections to the SNc. C, Representative locomotor tracing records, indicating that inhibition of SNr GABA neurons was rewarding in vGAT-cre mice (with NpHR expression in SNr GABA neurons), whereas optical activation of SNr GABA neurons in vGAT-cre mice (with ChR2 expression in SNr GABA neurons) was neither rewarding nor aversive. vGAT-cre mice with SNr NpHR-eYFP expression $(n=9)$ spent more time on the green laser $(532 \mathrm{~nm})$-paired compartment, but no change in place preference was observed in vGAT-cre mice transfected with SNr ChR2-eYFP expression ( $n=6)$. D, Optical RTPP across 5 consecutive test sessions, illustrating that only vGAT-cre mice with NpHR expression in SNr GABA neurons showed significant laser-paired place preference. $\boldsymbol{E}$, The general experimental procedures of olCSS. $\boldsymbol{F}$, Representative olCSS records, illustrating that vGAT-cre mice with intra-SNr NpHR microinjections exhibited robust olCSS, whereas in mice with intra-SNr AAV-eYFP control virus microinjections did not. G, The time courses of olCSS during $12 \mathrm{~d}$ of olCSS training, indicating that optical inhibition of SNr GABA neurons is rewarding. ${ }^{*} p<0.05$ as compared to the baseline (BL) (D) or eYFP control virus group (G).

the eYFP expression in DA neurons in the VTA or SNc neurons, indicating that $\mathrm{AAV}$ vectors were injected in the designated regions. Figures $8 C$ and $9 B$ show eYFP expression in the $\mathrm{SNr}$ after intra-SNr virus injections. Figure 11 shows the images from 2 additional vGAT-cre mice (Fig. 11A,B), illustrating that eYFP is expressed mainly in the SNr, not in the SNc or VTA. Figure $11 B, C$ shows eYFP expression under higher magnifications, illustrating that eYFP-expressing GABA neurons are found mainly in the $\mathrm{SNr}$, whereas a very few eYPF-expressing neurons are found in the SNc. In addition, direct GABAergic projections from the SNr to the SNc can be seen in Figure $11 A-C$.

Figure $11 D$ shows a summary diagram, highlighting the major findings in this study that more MORs are expressed in SNr GABA neurons than in VTA GABA neurons and that MORs in GABA neurons in the $\mathrm{SNr}$ (or $\mathrm{SNr} \rightarrow \mathrm{SNc}$ GABA pathway) play a more important role than in the VTA in opioid reward and relapse.

\section{Discussion}

The main findings in the present study are as follows: (1) there is no convincing evidence supporting a critical role of VTA GABA neurons in opioid reward, as indicated by the low level of MOR expression in VTA GABA neurons and the absence of effects of optogenetic activation of VTA GABA neurons on heroin selfadministration; and (2) our findings from gene to behavior indicate that GABA neurons in the SNr play a critical role in opioid reward and relapse.

Mesolimbic DA is important in opioid reward

Early electrophysiological studies indicate that stimulation of MORs can directly inhibit VTA GABA neurons, leading to rapid excitation of neighboring VTA DA neurons (Gysling and Wang, 1983; Johnson and North, 1992; Margolis et al., 2014). This 


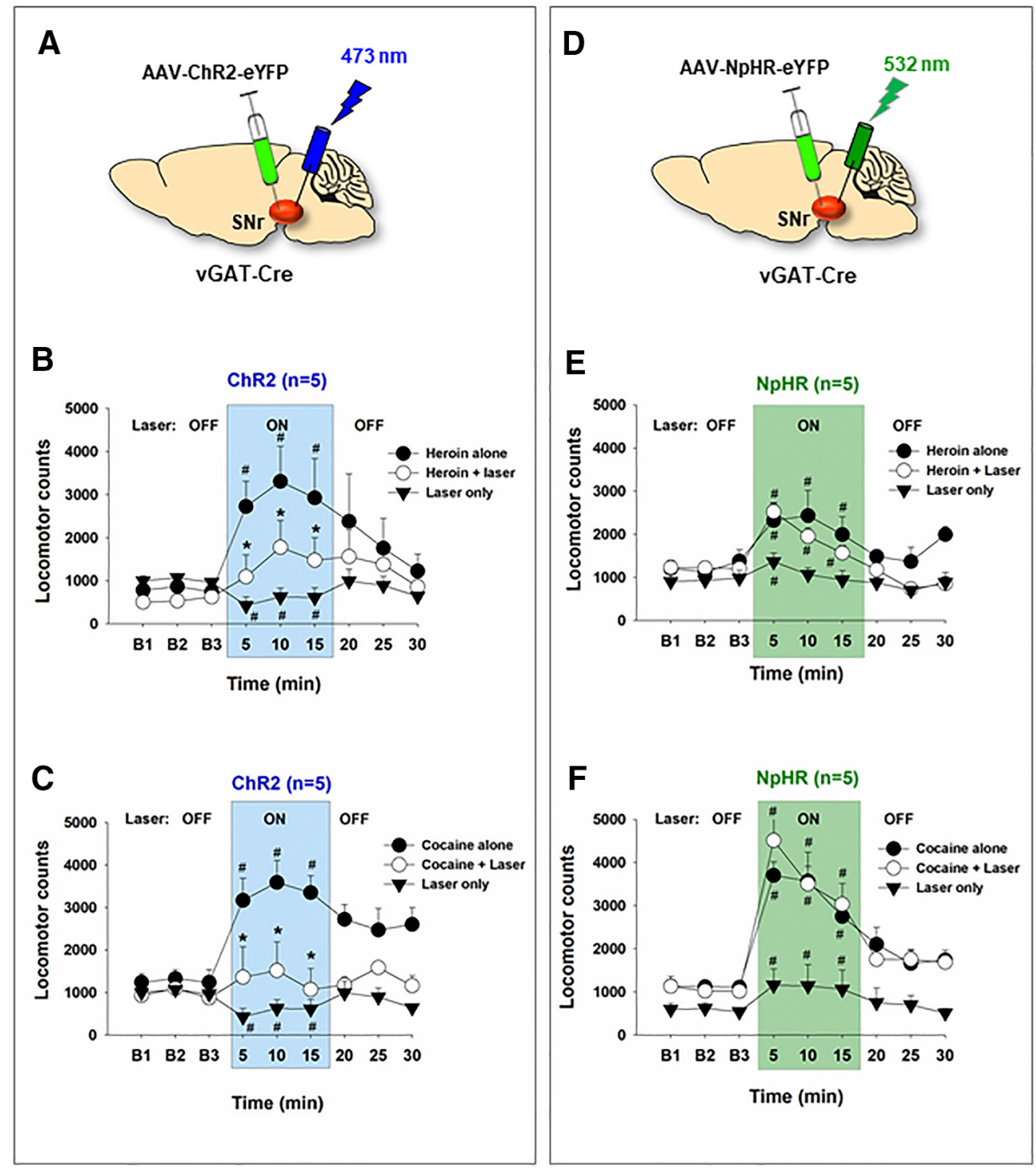

Figure 10. The effects of optical manipulation of SNr GABA neurons on basal and heroin (or cocaine)-enhanced locomotion. $A$, General experimental procedures with intra-SNr AAV-ChR2eYFP microinjections $(n=5)$. B, Optical activation of SNr GABA neurons decreased basal level of locomotion and attenuated heroin (1 mg/kg, i.p.)-induced hyperlocomotion. $\boldsymbol{C}$, Optical activation of SNr GABA neurons also attenuated cocaine (10 mg/kg, i.p.)-induced increases in open-field locomotion. $\boldsymbol{D}$, General experimental procedures with intra-SNr AAV-NpHR-eYPF microinjections $(n=5)$. $\boldsymbol{E}$, Optogenetic inhibition of SNr GABA neurons potentiated basal level of locomotion but failed to alter heroin-induced increased in locomotion. $\boldsymbol{F}$, Optical inhibition of SNr GABA neurons also failed to alter cocaine-induced increases in locomotion. ${ }^{*} p<0.05$ compared to baseline before drug injection or laser stimulation. ${ }^{*} p<0.05$ compared to heroin or cocaine alone group.

canonical two-neuron model hypothesis was supported by a series of behavioral findings, as discussed in the Introduction and in other reports (Galaj et al., 2020b; Fields and Margolis, 2015). It is also supported by a recent finding that heroin can activate a subpopulation of DA neurons in the medial part of the VTA that project to the medial shell of the NAc (Corre et al., 2018). Chemogenetic inhibition of VTA DA neurons decreased heroin self-administration (Corre et al., 2018). As mentioned in the Introduction, these findings have been challenged by other studies, suggesting that DA plays a more important role in psychostimulant than opioid reward (Ettenberg et al., 1982; Hnasko et al., 2005; Badiani et al., 2011). In the present study, we demonstrated that optogenetic activation of VTA DA neurons is rewarding, whereas activation of VTA GABA neurons is aversive, as assessed by optogenetic RTPP and oICSS. The latter finding is consistent with a previous report (Tan et al., 2012). Importantly, response-contingent optogenetic inhibition of VTA DA neurons decreased heroin self-administration. These new findings provide additional behavioral evidence supporting the role of DA in opioid reward.

VTA GABA neurons play a limited role in opioid reward Another important finding in the present study is that VTA GABA neurons play a limited role in opioid reward, as indicated by the findings that optogenetic activation of VTA GABA neurons failed to alter heroin self-administration, but significantly inhibited cocaine self-administration in vGAT-Cre mice. In addition, intra-VTA microinjections of naloxonazine partially attenuated heroin reward only when the heroin dose was very low $(0.0125 \mathrm{mg} / \mathrm{kg} /$ infusion$)$. These findings directly challenge the VTA GABA-DA hypothesis. In line with our findings are previous studies reporting a low level of MORs in the VTA (Tempel and Zukin, 1987; Méndez et al., 2003) and demonstrating that VTA DA neurons receive dense GABAergic inputs from brain regions, such as the NAc, ventral pallidum, and RMTg 
A

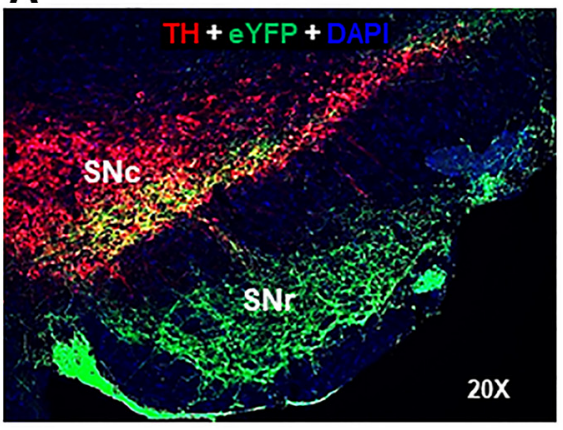

C

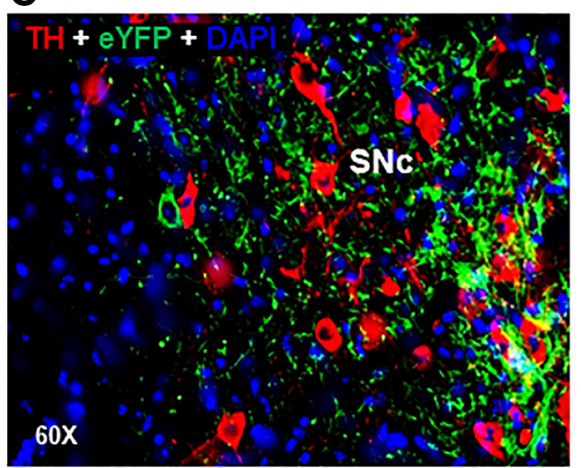

B

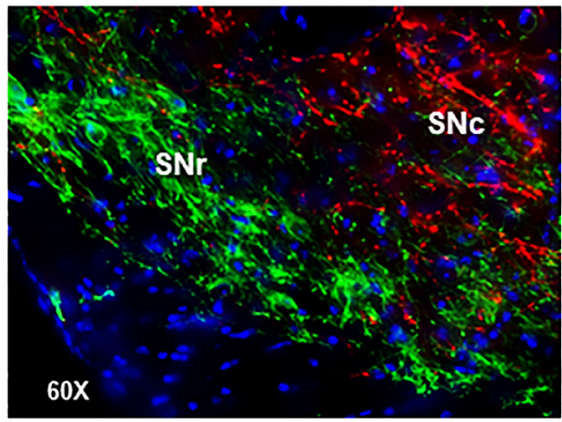

D

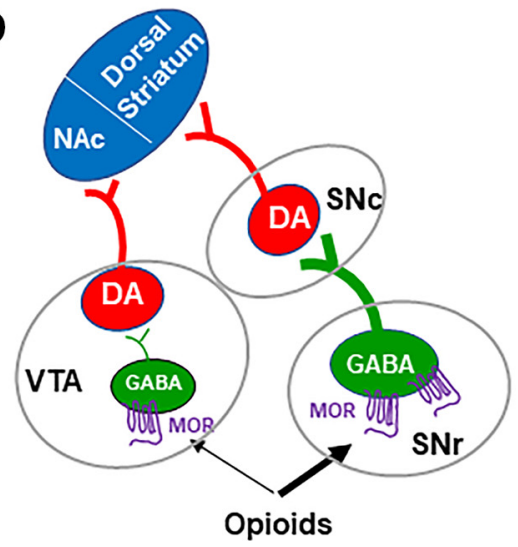

Figure 11. Verification of the locations of viral expression in the brain after the completion of the optogenetic experiments. $\boldsymbol{A}$, Representative images from another VGAT-cre mouse, showing eYFP expression in the SNr, which project to the SNc. $B, C$, Representative images under high magnifications $(60 \times)$, illustrating that eYFP-expressing GABA neurons are mainly located in the $\mathrm{SNr}(\boldsymbol{B})$, not in the $\mathrm{SNc}(\boldsymbol{C})$. D , Summary diagram, illustrating that more MORs are expressed in GABA neurons in the SNr than in the VTA and SNr GABA neurons project to SNc DA neurons. Thus, both the mesolimbic (VTA $\rightarrow$ NAc) and nigrostriatal $(\mathrm{SNr} \rightarrow \mathrm{SNc} \rightarrow$ dorsal striatum) DA circuits underlie opioid reward and relapse.

(Vaccarino et al., 1985; Martin et al., 2002; Jalabert et al., 2011; Matsui and Williams, 2011; Jhou et al., 2012; Lecca et al., 2012; Matsui et al., 2014; Steidl et al., 2017). Recent studies suggest that RMTg GABA neurons might be one of the major targets that opioids act (Jhou et al., 2012; Matsui et al., 2014; Steidl et al., 2017). VTA DA neurons are modulated mainly by GABAergic afferents from the RMTg rather than local GABA neurons in the VTA (Jhou et al., 2009; Jalabert et al., 2011; Steidl et al., 2015).

\section{MORs are highly expressed in GABA neurons in the $\mathrm{SNr}$ and RMTg}

A third important finding in this study is that the MOR mRNA is highly expressed in GABA neurons in the $\mathrm{SNr}$ and the tail of the VTA (RMTg), not in DA neurons in the VTA or SNc. By using double immunostaining and RNAscope ISH assays, we found that a majority of SNr and RMTg neurons are GABAergic and a vast majority of VTA and SNc neurons are dopaminergic. There are $\sim 70 \%$ of GABA neurons in the RMTg that express MORs and $\sim 50 \%$ of GABA neurons in the SNr express MORs, whereas in the VTA there are $<30 \%$ of GABA neurons expressing MORs. These findings at least partially explain why optogenetic activation of VTA GABA neurons or intra-VTA blockade of MORs failed to significantly alter heroin self-administration as shown in the present study.

The SNr: a critical hub in the nigrostriatal DA system An unexpected finding is that optogenetic stimulation of DA neurons in the SNc is also rewarding, as assessed by oICSS in

DAT-cre mice, to a degree similar to optogenetic stimulation of VTA DA neurons, suggesting an important role of SNc DA neurons in brain reward function (Rossi et al., 2013; Ilango et al., 2014). The SNr is anatomically adjacent to the SNc and functionally modulates SNc DA neuronal activity. $\mathrm{DA}$ neurons in the $\mathrm{SNc}$ receive dense GABAergic projections from the $\mathrm{SNr}$, as shown here and by others (Sanderson et al., 1986; Deniau and Chevalier, 1992; Tepper and Lee, 2007), and project mainly to the dorsal striatum (Ungerstedt, 1976; Hattori et al., 1991).

This nigrostriatal DA system is traditionally thought to modulate locomotion (Ungerstedt, 1976). However, growing evidence indicates that this system is also involved in brain reward function. Earlier studies indicate that electrical stimulation of the $\mathrm{SNc}$ is rewarding (Corbett and Wise, 1980; Wise, 1981; Rossi et al., 2013). In the present study, we found that optogenetic inhibition of SNr GABA neurons is also rewarding, as assessed by oICSS in vGAT-cre mice. However, little is known about how SNr GABA neurons modulate brain reward function.

Several lines of evidence suggest that SNr GABA neurons synapse on SNc DA neurons and modulate DA neuron activity. For example, intravenous administration of morphine decreases the activity of SNr GABA neurons but increases the firing rate of SNc DA neurons (Finnerty and Chan, 1979; Hommer and Pert, 1983; Melis et al., 2000). Similarly, intra-SNr application of morphine excites SNc DA neurons and increases striatal DA release (Matthews and German, 1984; You et al., 1996). Local injections of the D1R agonist SKF 38393 into the dorsal striatum increases GABA release in the ipsilateral $\mathrm{SNr}$, followed by prolonged decreases in the striatal DA release (You et al., 1994). In the present study, we found that eYFP-expressing GABA neurons in the SNr may directly project to the SNc. Thus, the rewarding effects produced by inhibition of SNr GABA neurons may be mediated by disinhibition of SNc DA neurons.

The $\mathrm{SNr}$ is critically involved in opioid reward and relapse As stated above, in the $\mathrm{SNr}, \sim 50 \%$ of GABA neurons express MORs, suggesting importance of SNr MORs in opioid reward. Since the SNr has been largely ignored in opioid research, we extensively explored the role of MORs in SNr GABA neurons in opioid reward and relapse in this study. Intra-SNr microinjections of the MOR antagonists increased heroin self-administration. Given that naloxonazine-induced changes in the self-administration pattern resemble the changes observed when the heroin dose is reduced, we interpret naloxonazine-induced increases in heroin self-administration as compensatory increase due to a reduction in opioid reward (Yokel and Wise, 1976). To further determine the role of SNr GABA neurons in opioid reward, we used optogenetic approaches to manipulate $\mathrm{SNr}$ 
GABA neurons in vGAT-cre mice. We found that activation of SNr GABA neurons was neither rewarding nor aversive, which contrasts with the aversive effects produced by optical activation of VTA GABA neurons. However, inhibition of SNr GABA neurons was rewarding, suggesting that $\mathrm{SNr}$ GABA neurons are tonically activated under physiological conditions. In addition, optogenetic activation of SNr GABA neurons decreased heroin reward (in a manner similar to MOR antagonism) and heroinprimed reinstatement, suggesting the involvement of SNr GABA neurons in opioid-induced behaviors. These findings suggest that opioids may also activate the nigrostriatal DA pathway, producing rewarding effects, which well explains why selective blockade or chemical lesions of DA terminals in the NAc selectively altered cocaine, but not heroin, self-administration or conditioned place preference (Ettenberg et al., 1982; Pettit et al., 1984; Dworkin et al., 1988; Gerrits et al., 1994; Badiani et al., 2011; Nutt et al., 2015).

We note that optogenetic inhibition of VTA DA neurons caused decreases, whereas optogenetic activation of SNr GABA neurons caused increases, in heroin self-administration rates. One possible explanation for the opposite behavioral alterations related to a reduction of opioid reward is that inhibition of DA neurons causes a substantial loss in opioid reward, leading to a reduction or cessation in heroin self-administration. In contrast, activation of SNr GABA neurons may cause only a partial reduction in opioid reward, leading to a compensatory increase in drug intake. This is consistent with previous reports that DA receptor antagonism produces biphasic effects on drug self-administration: low doses of DA receptor antagonists partially reduce drug reward leading to compensatory increases in responding, whereas high doses of DA receptor antagonists cause a substantial loss in drug reward, resulting in cessation of responding (Yokel and Wise, 1976).

In conclusion, in this study, we found that VTA GABA neurons play a limited role in opioid reward, which challenges the traditional dogma that opioid reward is mediated by stimulation of MORs in VTA GABA neurons. In contrast, we identified MORs in GABA neurons in the SNr and RMTg that appear to be important elements of the mesolimbic and nigrostriatal DA circuitries involved in opioid reward and relapse.

\section{References}

Badiani A, Belin D, Epstein D, Calu D, Shaham Y (2011) Opiate versus psychostimulant addiction: the differences do matter. Nat Rev Neurosci 12:685-700.

Bals-Kubik R, Ableitner A, Herz A, Shippenberg TS (1993) Neuroanatomical sites mediating the motivational effects of opioids as mapped by the conditioned place preference paradigm in rats. J Pharmacol Exp Ther 264:489-495.

Bolam JP, Smith Y (1990) The GABA and substance P input to dopaminergic neurones in the substantia nigra of the rat. Brain Res 529:57-78.

Bozarth MA, Wise RA (1981) Intracranial self-administration of morphine into the ventral tegmental area in rats. Life Sci 28:551-555.

Corbett D, Wise RA (1980) Intracranial self-stimulation in relation to the ascending dopaminergic systems of the midbrain: a moveable electrode mapping study. Brain Res 185:1-15.

Corre J, van Zessen R, Loureiro M, Patriarchi T, Tian L, Pascoli V, Lüscher C (2018) Dopamine neurons projecting to medial shell of the nucleus accumbens drive heroin reinforcement. Elife 7:e39945.

David V, Cazala P (1994) A comparative study of self-administration of morphine into the amygdala and the ventral tegmental area in mice. Behav Brain Res 65:205-211.

Deniau JM, Chevalier G (1992) The lamellar organization of the rat substantia nigra pars reticulata: distribution of projection neurons. Neuroscience 46:361-377.
Devine DP, Wise RA (1994) Self-administration of morphine, DAMGO, and DPDPE into the ventral tegmental area of rats. J Neurosci 14:1978-1984.

Dworkin SI, Guerin GF, Co C, Goeders NE, Smith JE (1988) Lack of an effect of 6-hydroxydopamine lesions of the nucleus accumbens on intravenous morphine self-administration. Pharmacol Biochem Behav 30:1051-1057.

Ettenberg A, Pettit HO, Bloom FE, Koob GF (1982) Heroin and cocaine intravenous self-administration in rats: mediation by separate neural systems. Psychopharmacology 78:204-209.

Fields HL, Margolis EB (2015) Understanding opioid reward. Trends Neurosci 38:217-225.

Finnerty EP, Chan SH (1979) Morphine suppression of substantia nigra zona reticulata neurons in the rat: implicated role for a novel striatonigral feedback mechanism. Eur J Pharmacol 59:307-310.

Galaj E, Bi GH, Yang HJ, Xi ZX (2020a) Cannabidiol attenuates the rewarding effects of cocaine by CB2, 5-TH1A and TRPV1 receptor mechanisms. Neuropharmacology 167:107740.

Galaj E, Newman AH, Xi ZX (2020b) Dopamine D3 receptor-based medication development for the treatment of opioid use disorder: rationale, progress, and challenges. Neurosci Biobehav Rev 114:38-52.

Gerrits MA, Ramsey NF, Wolterink G, van Ree JM (1994) Lack of evidence for an involvement of nucleus accumbens dopamine D1 receptors in the initiation of heroin self-administration in the rat. Psychopharmacology 114:486-494.

Gysling K, Wang RY (1983) Morphine-induced activation of A10 dopamine neurons in the rat. Brain Res 277:119-127.

Hattori T, Takada M, Moriizumi T, Van der Kooy D (1991) Single dopaminergic nigrostriatal neurons form two chemically distinct synaptic types: possible transmitter segregation within neurons. J Comp Neurol 309: 391-401.

Hjelmstad GO, Xia Y, Margolis EB, Fields HL (2013) Opioid modulation of ventral pallidal afferents to ventral tegmental area neurons. J Neurosci 33:6454-6459.

Hnasko TS, Sotak BN, Palmiter RD (2005) Morphine reward in dopaminedeficient mice. Nature 438:854-857.

Hommer DW, Pert A (1983) The actions of opiates in the rat substantia nigra: an electrophysiological analysis. Peptides 4:603-608.

Ilango A, Kesner AJ, Keller KL, Stuber GD, Bonci A, Ikemoto S (2014) Similar roles of substantia nigra and ventral tegmental dopamine neurons in reward and aversion. J Neurosci 34:817-822.

Jalabert M, Bourdy R, Courtin J, Veinante P, Manzoni OJ, Barrot M, Georges F (2011) Neuronal circuits underlying acute morphine action on dopamine neurons. Proc Natl Acad Sci USA 108:16446-16450.

Jhou TC, Fields HL, Baxter MG, Saper CB, Holland PC (2009) The rostromedial tegmental nucleus (RMTg), a GABAergic afferent to midbrain dopamine neurons, encodes aversive stimuli and inhibits motor responses. Neuron 61:786-800.

Jhou TC, Xu SP, Lee MR, Gallen CL, Ikemoto S (2012) Mapping of reinforcing and analgesic effects of the mu opioid agonist endomorphin-1 in the ventral midbrain of the rat. Psychopharmacology (Berl) 224:303-312.

Johnson SW, North RA (1992) Opioids excite dopamine neurons by hyperpolarization of local interneurons. J Neurosci 12:483-488.

Kalivas PW (1993) Neurotransmitter regulation of dopamine neurons in the ventral tegmental area. Brain Res Rev 18:75-113.

Lecca S, Melis M, Luchicchi A, Muntoni AL, Pistis M (2012) Inhibitory inputs from rostromedial tegmental neurons regulate spontaneous activity of midbrain dopamine cells and their responses to drugs of abuse. Neuropsychopharmacology 37:1164-1176.

Margolis EB, Hjelmstad GO, Fujita W, Fields HL (2014) Direct bidirectional $\mu$-opioid control of midbrain dopamine neurons. J Neurosci 34:1470714716.

Martin TJ, Kim SA, Lyupina Y, Smith JE (2002) Differential involvement of mu-opioid receptors in the rostral versus caudal nucleus accumbens in the reinforcing effects of heroin in rats: evidence from focal injections of beta-funaltrexamine. Psychopharmacology (Berl) 161:152-159.

Matsui A, Williams JT (2011) Opioid-sensitive GABA inputs from rostromedial tegmental nucleus synapse onto midbrain dopamine neurons. J Neurosci 31:17729-17735.

Matsui A, Jarvie BC, Robinson BG, Hentges ST, Williams JT (2014) Separate GABA afferents to dopamine neurons mediate acute action of opioids, development of tolerance, and expression of withdrawal. Neuron 82: 1346-1356. 
Matthews RT, German DC (1984) Electrophysiological evidence for excitation of rat ventral tegmental area dopamine neurons by morphine. Neuroscience 11:617-625.

Melis M, Gessa GL, Diana M (2000) Different mechanisms for dopaminergic excitation induced by opiates and cannabinoids in the rat midbrain. Prog Neuropsychopharmacol Biol Psychiatry 24:993-1006.

Méndez M, Leriche M, Carlos Calva J (2003) Acute ethanol administration transiently decreases $\left[{ }^{3} \mathrm{H}\right]$-DAMGO binding to mu opioid receptors in the rat substantia nigra pars reticulata but not in the caudate-putamen. Neurosci Res 47:153-160.

Nutt DJ, Lingford-Hughes A, Erritzoe D, Stokes PR (2015) The dopamine theory of addiction: 40 years of highs and lows. Nat Rev Neurosci 16:305-312.

Olmstead MC, Franklin KB (1997) The development of a conditioned place preference to morphine: effects of microinjections into various CNS sites. Behav Neurosci 111:1324-1334.

Pettit HO, Ettenberg A, Bloom FE, Koob GF (1984) Destruction of dopamine in the nucleus accumbens selectively attenuates cocaine but not heroin self-administration in rats. Psychopharmacology 84:167-173.

Phillips AG, LePiane FG (1980) Reinforcing effects of morphine microinjection into the ventral tegmental area. Pharmacol Biochem Behav 12:965968.

Rossi MA, Sukharnikova T, Hayrapetyan VY, Yang L, Yin HH (2013) Operant self-stimulation of dopamine neurons in the substantia nigra. PLoS One 8:e65799.

Sanderson P, Mavoungou R, Albe-Fessard D (1986) Changes in substantia nigra pars reticulata activity following lesions of the substantia nigra pars compacta. Neurosci Lett 67:25-30.

Steidl S, Myal S, Wise RA (2015) Supplemental morphine infusion into the posterior ventral tegmentum extends the satiating effects of self-administered intravenous heroin. Pharmacol Biochem Behav 134:1-5.

Steidl S, Wasserman DI, Blaha CD, Yeomans JS (2017) Opioid-induced rewards, locomotion, and dopamine activation: a proposed model for control by mesopontine and rostromedial tegmental neurons. Neurosci Biobehav Rev 83:72-82.

Tan KR, Yvon C, Turiault M, Mirzabekov JJ, Doehner J, Labouèbe G, Deisseroth K, Tye KM, Lüscher C (2012) GABA neurons of the VTA drive conditioned place aversion. Neuron 73:1173-1183.

Tempel A, Zukin RS (1987) Neuroanatomical patterns of the mu, delta, and kappa opioid receptors of rat brain as determined by quantitative in vitro autoradiography. Proc Natl Acad Sci USA 84:4308-4312.

Tepper JM, Lee CR (2007) GABAergic control of substantia nigra dopaminergic neurons. Prog Brain Res 160:189-208.
Ungerstedt U (1976) 6-Hydroxydopamine-induced degeneration of the nigrostriatal dopamine pathway: the turning syndrome. Pharmacol Ther B 2:37-40.

Vaccarino FJ, Bloom FE, Koob GF (1985) Blockade of nucleus accumbens opiate receptors attenuates intravenous heroin reward in the rat. Psychopharmacology 86:37-42.

Wang XF, Bi GH, He Y, Yang HJ, Gao JT, Okunola-Bakare OM, Slack RD, Gardner EL, Xi ZX, Newman AH (2015) R-modafinil attenuates nicotine-taking and nicotine-seeking behavior in alcohol-preferring rats. Neuropsychopharmacology 40:1762-1771.

Watabe-Uchida M, Zhu L, Ogawa SK, Vamanrao A, Uchida N (2012) Whole-brain mapping of direct inputs to midbrain dopamine neurons. Neuron 74:858-873.

Welzl H, Kuhn G, Huston JP (1989) Self-administration of small amounts of morphine through glass micropipettes into the ventral tegmental area of the rat. Neuropharmacology 28:1017-1023.

Wise RA (1981) Intracranial self-stimulation: mapping against the lateral boundaries of the dopaminergic cells of the substantia nigra. Brain Res 213:190-194

Wise RA (1989) Opiate reward: sites and substrates. Neurosci Biobehav 13:129-133.

Xi ZX, Gilbert J, Campos AC, Kline N, Ashby CR Jr, Hagan JJ, Heidbreder CA, Gardner EL (2004) Blockade of mesolimbic dopamine D3 receptors inhibits stress-induced reinstatement of cocaine-seeking in rats. Psychopharmacology (Berl) 176:57-65.

Xi ZX, Peng XQ, Li X, Song R, Zhang HY, Liu QR, Yang HJ, Bi GH, Li J, Gardner EL (2011) Brain cannabinoid $\mathrm{CB}_{2}$ receptors modulate cocaine's actions in mice. Nat Neurosci 14:1160-1166.

Yokel RA, Wise RA (1976) Attenuation of intravenous amphetamine reinforcement by central dopamine blockade in rats. Psychopharmacology $48: 311-318$

You ZB, Herrera-Marschitz M, Nylander I, Goiny M, Kehr J, Ungerstedt U, Terenius L (1996) Effect of morphine on dynorphin B and GABA release in the basal ganglia of rats. Brain Res 710:241-248.

You ZB, Herrera-Marschitz M, Nylander I, Goiny M, O'Connor WT, Ungerstedt U, Terenius L (1994) The striatonigral dynorphin pathway of the rat studied with in vivo microdialysis: II. Effects of dopamine D1 and D2 receptor agonists. Neuroscience 63:427-434.

Zangen A, Ikemoto S, Zadina JE, Wise RA (2002) Rewarding and psychomotor stimulant effects of endomorphin-1: anteroposterior differences within the ventral tegmental area and lack of effect in nucleus accumbens. J Neurosci 22:7225-7233. 